\title{
Microstructural and fatigue crack growth behavior inhomogeneity of trace Sc added 7085 alloy friction stir welded joint
}

\author{
Zixing Jia ${ }^{1}$, Lili Wei ${ }^{1}$, Hongfeng Huang ${ }^{1}$, Chongyu Liu ${ }^{1}$, Hongjie Jiang ${ }^{1}$, and Xuda Xu \\ ${ }^{1}$ Guilin University of Technology \\ ${ }^{2}$ Sanshui Fenglv Aluminium Co., Ltd.
}

August 12, 2020

\begin{abstract}
The inhomogeneity of friction stir weld (FSW) joint of a 7085 Al-based alloy containing trace Sc was investigated by comparing the hardening phase morphology, grain structure, mechanical properties and fatigue crack growth (FCG) behavior in based metal (BM), heat-affected zone (HAZ) and weld nugget zone (WNZ). The results showed that microstructural evolution during FSW was remarkably affected by Sc addition. The recrystallization and growth of grains in BM and HAZ were restrained by coherent $\mathrm{Al} 3(\mathrm{Sc}, \mathrm{Zr})$ particles. In HAZ, partially dissolution and slight growth of precipitates resulted in softening but contributed to enhance the FCG resistance according to shear mechanism. In WNZ, high frictional heating and intense plastic deformation induced recrystallization and supersaturated solid solution which decomposed to form new reprecipitates, including many new GPII zones, ' phases and some coarse equilibrium phases attached to grown incoherent Al3(Sc,Zr). Owing to combined influences of fine random orientated grain structure and reprecipitates, WNZ possessed the best fatigue endurance.
\end{abstract}

\section{Microstructural and fatigue crack growth behaviorinhomogeneity of trace Sc added 7085 alloy friction stir welded joint}

Zixing Jia ${ }^{2}$, Lili Wei ${ }^{1,2}, 11^{*}$ Corresponding author 1. Tel.: +86 13517739930. E-mail address:hhfwll@163.com. (Lili Wei), Hongfeng Huang ${ }^{1,2}, 22^{*}$ Corresponding author 2. Tel.: +86 13517738716. E-mail address:csuworld@163.com.(Hongfeng Huang), Chongyu Liu ${ }^{2}$, Hongjie Jiang ${ }^{2}$, Xuda Xu ${ }^{3}$

${ }^{1}$ Key Laboratory of New Processing Technology for Nonferrous Metal \& Materials, Guilin University of Technology, Ministry of Education, Guilin 541004, China

${ }^{2}$ College of Materials Science and Engineering, Guilin University of Technology, Guilin 541004, China

${ }^{3}$ Sanshui Fenglv Aluminium Co., Ltd., Foshan, 528000, China

\section{Abstract}

The inhomogeneity of friction stir weld (FSW) joint of a 7085 Al-based alloy containing trace Sc was investigated by comparing the hardening phase morphology, grain structure, mechanical properties and fatigue crack growth (FCG) behavior in based metal (BM), heat-affected zone (HAZ) and weld nugget zone (WNZ). The results showed that microstructural evolution during FSW was remarkably affected by Sc addition. The recrystallization and growth of grains in $\mathrm{BM}$ and $\mathrm{HAZ}$ were restrained by coherent $\mathrm{Al}_{3}(\mathrm{Sc}, \mathrm{Zr})$ particles. In HAZ, partially dissolution and slight growth of precipitates resulted in softening but contributed to enhance the FCG resistance according to shear mechanism. In WNZ, high frictional heating and intense plastic deformation induced recrystallization and supersaturated solid solution which decomposed to form new reprecipitates, including many new GPII zones, ?' phases and some coarse ? equilibrium phases attached to grown incoherent $\mathrm{Al}_{3}(\mathrm{Sc}, \mathrm{Zr})$. Owing to combined influences of fine random orientated grain structure and reprecipitates, WNZ possessed the best fatigue endurance. 
Keywords:Aluminum alloy; Friction stir welding; Fatigue crack growth; Mechanical properties.

\section{Introduction}

$\mathrm{Al}-\mathrm{Zn}-\mathrm{Mg}-\mathrm{Cu}$ alloys (7xxx series) have been widely used in fields of aviation, aerospace, and civilian transport owing to their high strength to weight ratio, good fracture toughness and corrosion resistance [1-3]. For the preparation of complex structural parts in applications, the fusion welding technologies, e.g. Tungsten Inert Gas process, Gas Metal Arc Welding are the most used methods to join these high strength aluminum alloys. However, the joints made by these welding method showed high hot cracking susceptibility in $7 \mathrm{xxx}$ series alloys with high $\mathrm{Cu}$ content [4]. In addition to hot cracks, welding defects like porosity, lack of fusion and incomplete penetration also frequently took place. In order to avoid these problems associated with the liquid-solid coupling, a newly invented process, friction stir welding (FSW), which is a solid-state welding technique has been wildly used for defect-free and efficient welding of $7 \mathrm{xxx}$ series alloys [5, 6].

Unlike other conventional fusion welding methods, FSW is a complicated thermal-mechanical process. Because of the combined influence of frictional heating and intense plastic deformation, FSWed joints have generally inhomogeneous complex spatial arrangements of microstructure and mechanical properties [7-9]. In heat-treatable 2xxx and 7xxx alloys, recovery/recrystallization of substructure and re-dissolution/coarsening of hardening precipitates usually occur in weld joint due to great frictional heat generated between welding tool shoulder and workpieces [10], resulting pronounced degradation in mechanical properties as the absence of strengthening of dislocations, refinement structure and precipitates [11, 12]. In order to decrease these adverse effects, one approach is to reduce frictional heat, such as increasing tool traverse speed/rotation rate ratio, cooling FSW joint by water (underwater FSW). However, these low heat input FSW strategies would raise the possibility of non-welded groove on the root side of the weld [13,14]. Another alternative is to increase the recrystallization resistance of workpiece. It has been widely proved that trace Sc can improve recrystallization temperature of aluminum alloys due to the formation of $\mathrm{Al}_{3} \mathrm{Sc} / \mathrm{Al}_{3}(\mathrm{Sc}, \mathrm{Zr})$ precipitates in matrix $[15,16]$. The strength benefits of minor Sc addition have been demonstrated in 7055 and 7075 alloys [17, 18].

7085 aluminum alloy is a newer $7 \mathrm{xxx}$ alloy designed for aerospace applications. It has been widely used in many aircraft structural components due to high fracture toughness and low quench sensitivity [19-21]. Because the $\mathrm{Cu}$ content of the 7085 alloy exceeds $0.8 \mathrm{wt} . \%$, there are challenges in welding by using fusion welding technologies. As the outstanding advantages of FSW technology, the application of FSW in 7085

alloy aroused widespread concern in recent years. Xu et al. have investigated the FSW behaviors of 7085 alloy and discussed the effect of welding parameters on the microstructure inhomogeneity and mechanical properties of FSWed joint [5, 22-24]. However, because of the increasing use of 7085 alloy in fatigue critical applications, fatigue crack growth (FCG) behavior of the FSWed joint should be highly regarded, but the related appropriate experimental data is insufficient so far. Moreover, the influence of trace Sc addition on FSW behaviors of 7085 alloy has also rarely been reported, the effect of Sc on the microstructural evolution and mechanical properties, especially FCG in FSWed joint of alloy 7085 is not clear yet.

Therefore, in present work, a 7085-0.25Sc (wt.\%)-T6 Al alloy plates were welded by FSW. The microstructures (sub-structures, precipitates) and mechanical properties (hardness, tensile property and resistance to fatigue) of base metal (BM), heat-affected zone (HAZ) and weld nugget zone (WNZ) have been thoroughly investigated. The effects of Sc addition on the microstructures and properties, especially FCG inhomogeneity of FSWed joint were discussed in detail and elucidated.

\section{Experimental procedures}

\subsection{Materials and FSW parameters}

The 7085 with trace Sc alloy (hereinafter referred to as $7085 \mathrm{Sc}$ alloy) used in this study was supplied as 4.5 mm-thick rolled plates. The chemical composition is listed in Table 1 . A solid solution treatment $\left(480^{\circ} \mathrm{C} / 1 \mathrm{~h}\right.$, quenching in water) and aging annealing treatment $\left(120^{\circ} \mathrm{C} / 24 \mathrm{~h}\right.$, cooling in air) were applied to obtain $\mathrm{T} 6$ plate samples for welding. Before FSW process, the surfaces of plates were polished to remove the oxide 
layer for the purpose of minimizing welding defects in welding joint. The friction stir pin tool had a $15 \mathrm{~mm}$ concave shoulder, and a taper threaded probe whose diameter was $3.5 \mathrm{~mm}$ and long was $4 \mathrm{~mm}$. The welding direction was parallel to the rolling direction of the plates. The weld travelling speed was $100 \mathrm{~mm} / \mathrm{min}$ and ration rate of pin tool was $900 \mathrm{RPM}$.

Table 1. Chemical compositions (in wt.\%) of the $7085 \mathrm{Sc}$ alloy

\begin{tabular}{llllllll}
\hline $\mathrm{Zn}$ & $\mathrm{Mg}$ & $\mathrm{Cu}$ & $\mathrm{Sc}$ & $\mathrm{Zr}$ & $\mathrm{Si}$ & $\mathrm{Fe}$ & $\mathrm{Al}$ \\
\hline 7.91 & 1.39 & 1.79 & 0.26 & 0.12 & 0.14 & 0.06 & In balance \\
\hline
\end{tabular}

\subsection{Microstructural analysis}

The morphologies of grains and precipitates in BM, HAZ and WNZ were investigated. Optical microscopy (OM) observation was performed using Leica DFC 295 in polar light mode. Electron backscatter diffraction (EBSD) analyses were performed using ZEISS Sigma 300 field emission gun scanning electron microscope with a scanning step size of $0.15 \mu \mathrm{m}$. The EBSD data was analyzed by Channel 5 software to acquire microstructure statistics information. Boundaries with misorientations less than $15^{\circ}$ were defined as lowangle grain boundary (LAGB) and those with misorientations greater than $15^{\circ}$ were defined as high-angle grain boundary (HAGB), respectively. The scanning electron microscopy (SEM) observation of fracture surface were also operated by ZEISS Sigma 300 at $20 \mathrm{KV}$. Transmission electron microscopy (TEM) and high resolution transmission electron microscope (HRTEM) observations were carried out on FEI Tecnai $\mathrm{G}^{2}$ F20.

\subsection{Mechanical properties tests}

The microhardness arrangement of the entire weld cross section was detected by a LECO-AMH43 Vickers hardness tester with a testing load of 300 gf and a dwell time of $13 \mathrm{~s}$. The spacing between adjacent indentations was $0.5 \mathrm{~mm}$. Small dog-bone shape tensile testing specimens were machined by wire cut electrical discharge machining and tested on AGS-X-50kN testing machine at a strain rate of $1.3 \times 10^{-3} \mathrm{~s}^{-1}$. The FCG rate tests were performed on INSTRON-8801 testing machine at room temperature by using the compact tension (CT) specimens. All fatigue testing specimens were polished and tested with a load ratio of $\mathrm{R}=0.1$. Sine wave loading with a frequency of $10 \mathrm{~Hz}$ was used. The crack length was measured continuously by the compliance method with crack mouth clip gauge (3541-010M-040M-ST). The crack length and cycle number were recorded at every increment of $0.05 \mathrm{~mm}$ in crack length. Fig. 1 shows the dimensions of CT specimens and the sampling position. Fig. 2 shows the macro morphology of FSW joint and the fractured CT specimens after FCG test, illustrating that the welded joint shows good quality with no obvious weld defects. 


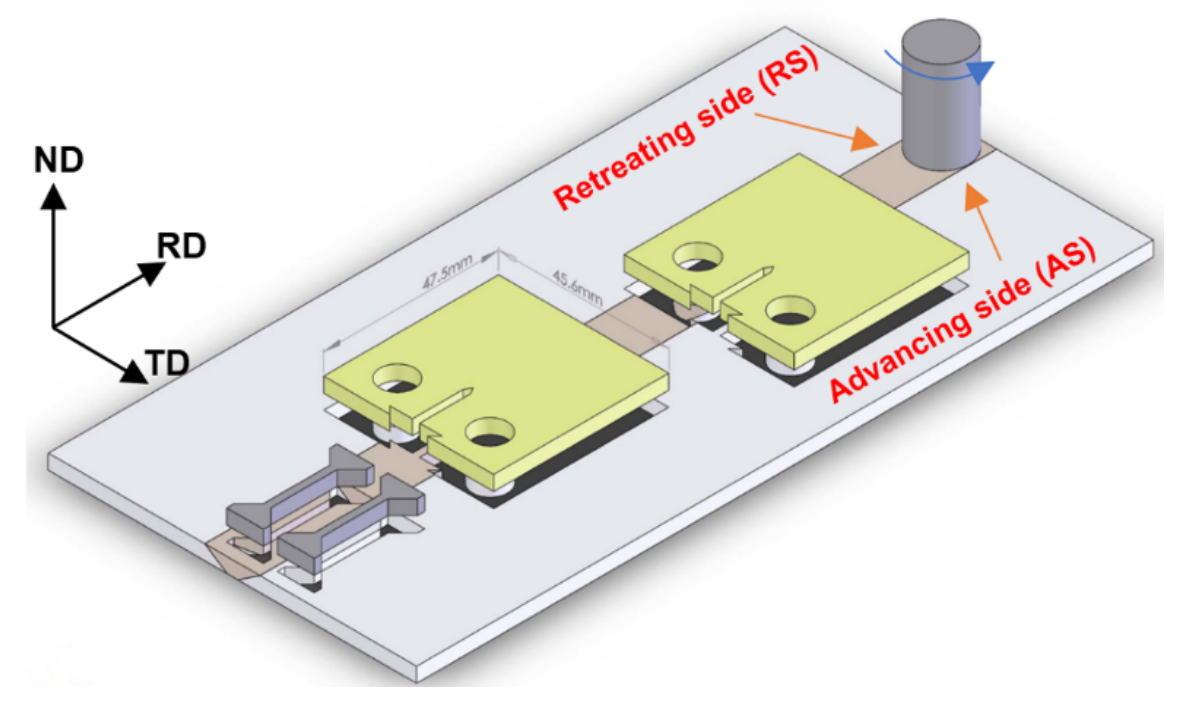

Fig. 1 Schematic diagrams showing the sample orientations

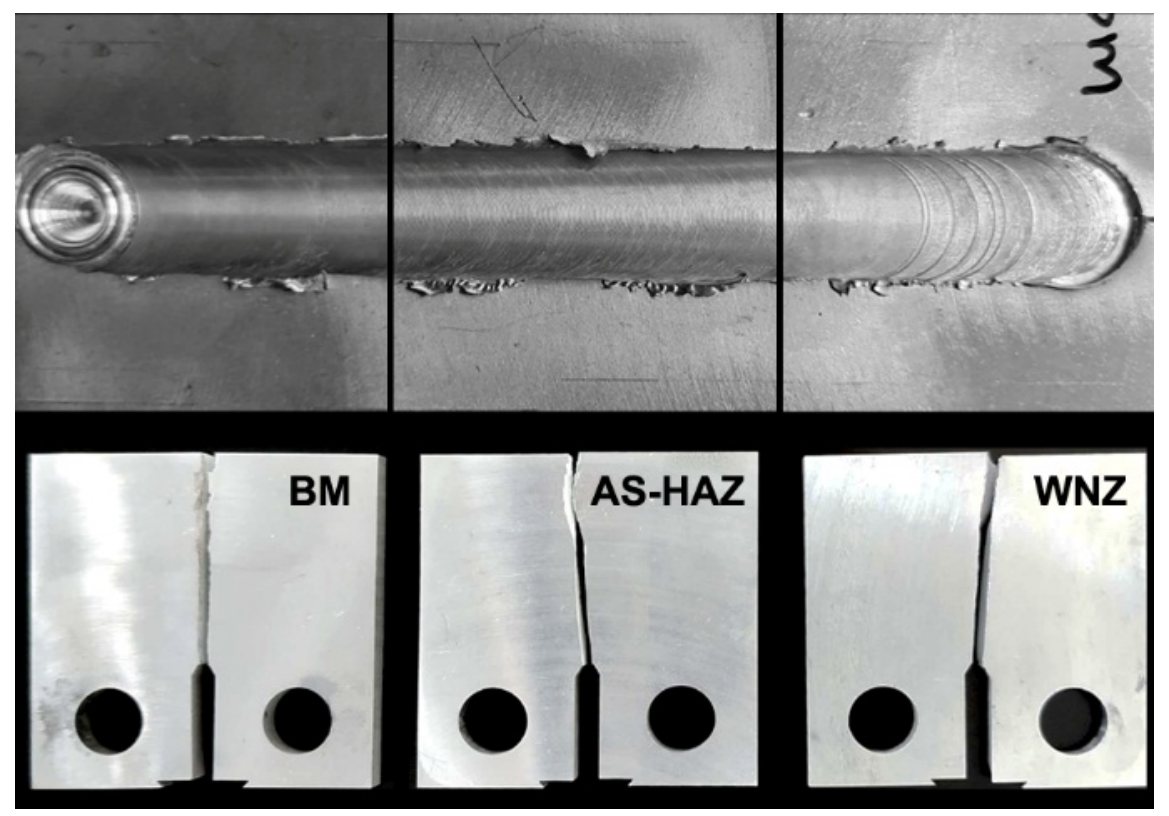

Fig. 2 Macro morphology of FSW joint and the fractured CT specimens

\section{Results}

\subsection{Hardness and tensile properties tests}

Fig. 3 shows the Vickers hardness arrangement in cross section of BM and FSWed joint. It reveals that an entire drop of hardness occurred after FSW as compared with BM. A roughly symmetrical micro-hardness distribution could be seen in welded joint, and two well pronounced softening bands with a distance of 10 $\mathrm{mm}$ from the joint center located in AS-HAZ and RS-HAZ, respectively. The softening band in AS-HAZ was about $5 \mathrm{~mm}$ in breadth, which was wider than the other one in RS-HAZ $(3 \mathrm{~mm})$. The average values of hardness in BM, AS-HAZ, RS-HAZ and WNZ were $186 \mathrm{HV}, 124 \mathrm{HV}, 132 \mathrm{HV}$, and $158 \mathrm{HV}$, respectively. 


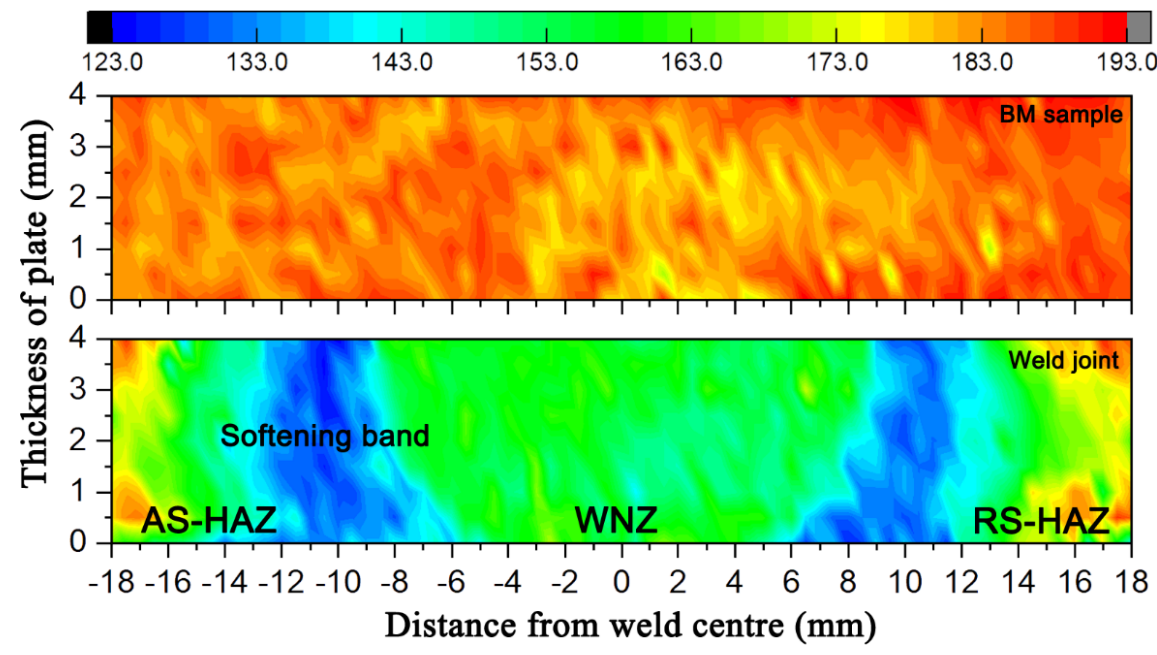

Fig. 3 Map of microhardness distribution along the transverse cross-section of BM and welding joint.

The tensile properties of BM, AS-HAZ and WNZ were tested and shown in Fig. 4, the results were consistent with hardness arrangement. BM showed the maximum yield strength (YS: $515 \mathrm{MPa}$ ), ultimate tensile strength (UTS: $593 \mathrm{MPa}$ ), while the YS and UTS in the softening position of AS-HAZ were the lowest, decreasing to $262 \mathrm{MPa}, 415 \mathrm{MPa}$ respectively. In contrast, WNZ processed the best elongation to failure and the strength was lower than BM but much higher than AS-HAZ.

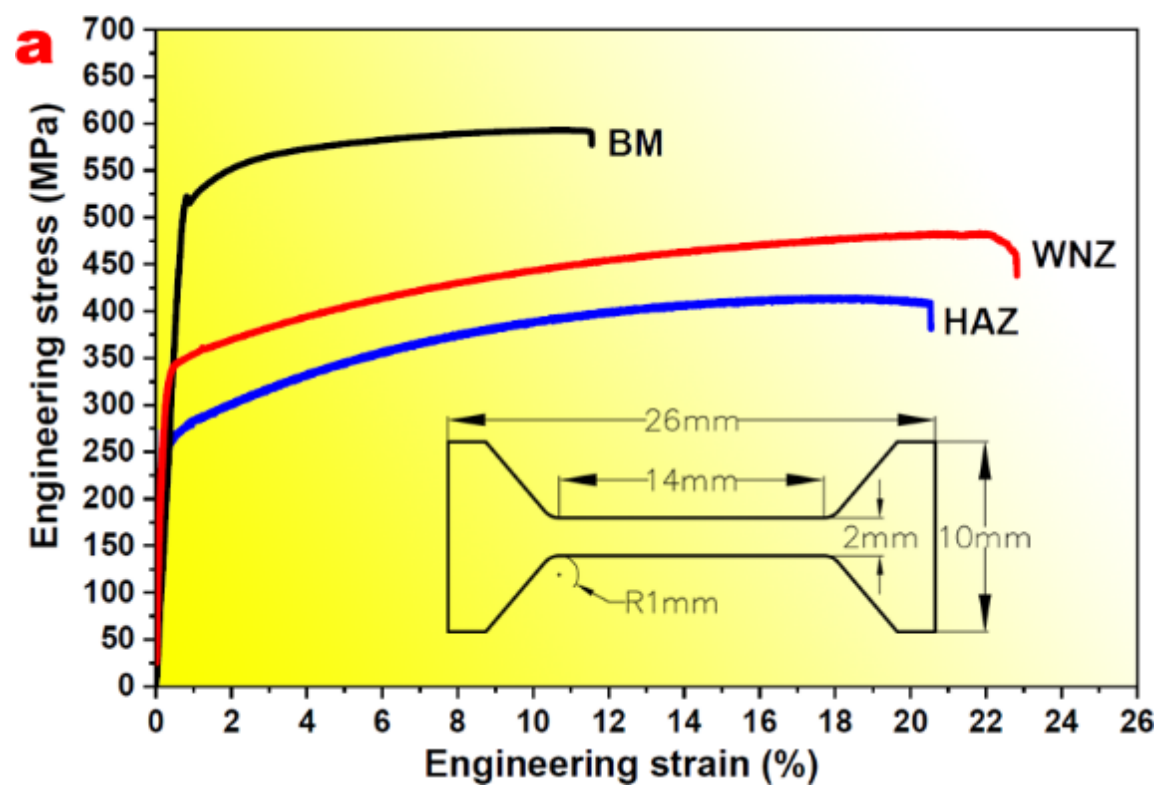




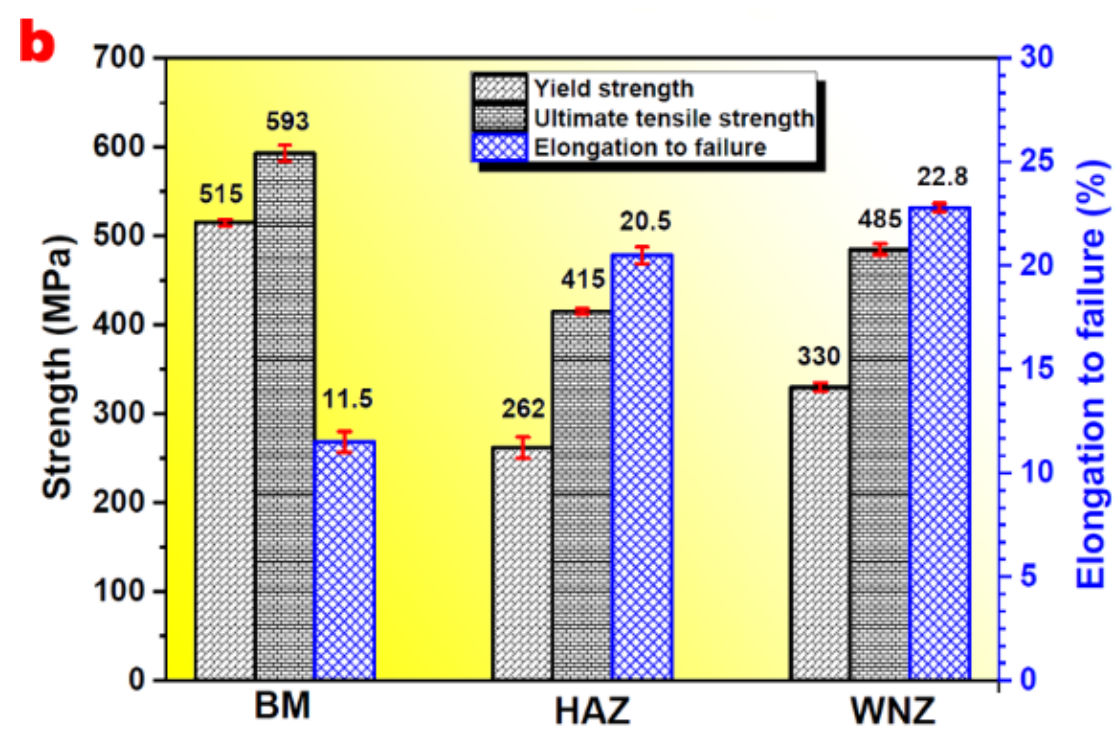

Fig. 4 The engineering stress-strain curves and detail values of YS, UTS and elongation to failure of BM, AS-HAZ and WNZ.

\subsection{OM, EBSD and TEM observation}

Fig. 5 shows the OM structure of welded joint. A homogeneous microstructure formed in WNZ and less obvious "S-line" defects can be observed (arrowed in the figure). A distinction among WNZ and HAZ can be seen from the significant variation of grain size. Both AS-HAZ and RS-HAZ maintained the similar pancake-shape grain structure as BM, indicating that FSW heating input had little or no influence on the grain structure in HAZ. Between WNZ and HAZ, there was a transition zone, thermo-mechanically affected zone (TMAZ) characterized by a highly deformed rheological structure due to the effects of shoulder-driven flow and pin-driven flow. A clear boundary between TMAZ and HAZ can be found in AS of joint, while the boundary in RS was not clear. According to the microhardness arrangement map shown in Fig. 3, the softening band with minimum hardness value did not located in TMAZ but in AS-HAZ. Therefore, in current study, attention was focused on BM, WNZ and softening band in AS-HAZ.

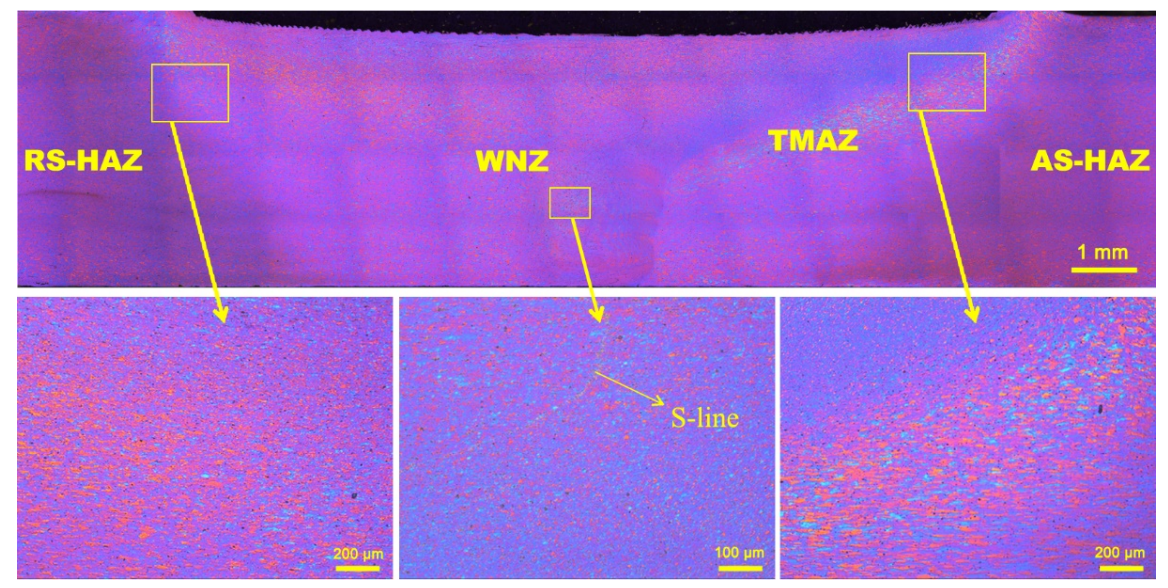

Fig. 5 OM image of FSW joint on cross section 
The detail statistical information of grain structure of BM, WNZ and softening band in AS-HAZ were further investigated by EBSD. The detailed statistical fractions of recrystallized, sub-structured, deformed structure were calculated and listed in the corresponding figures. According to the EBSD maps shown in Fig. 6, it can be found that BM and AS-HAZ mainly consisted of grains elongated along the rolling direction, many sub-grains inside grains as well as some small recrystallized grains in grain boundaries were distinguishable (Fig. 6a and 6c). In WNZ, the grain size dramatically decreased and the intragranular sub-grains entirely vanished (Fig. 6e), presenting a complete recrystallized equiaxed-grained structure (Fig. 6f).
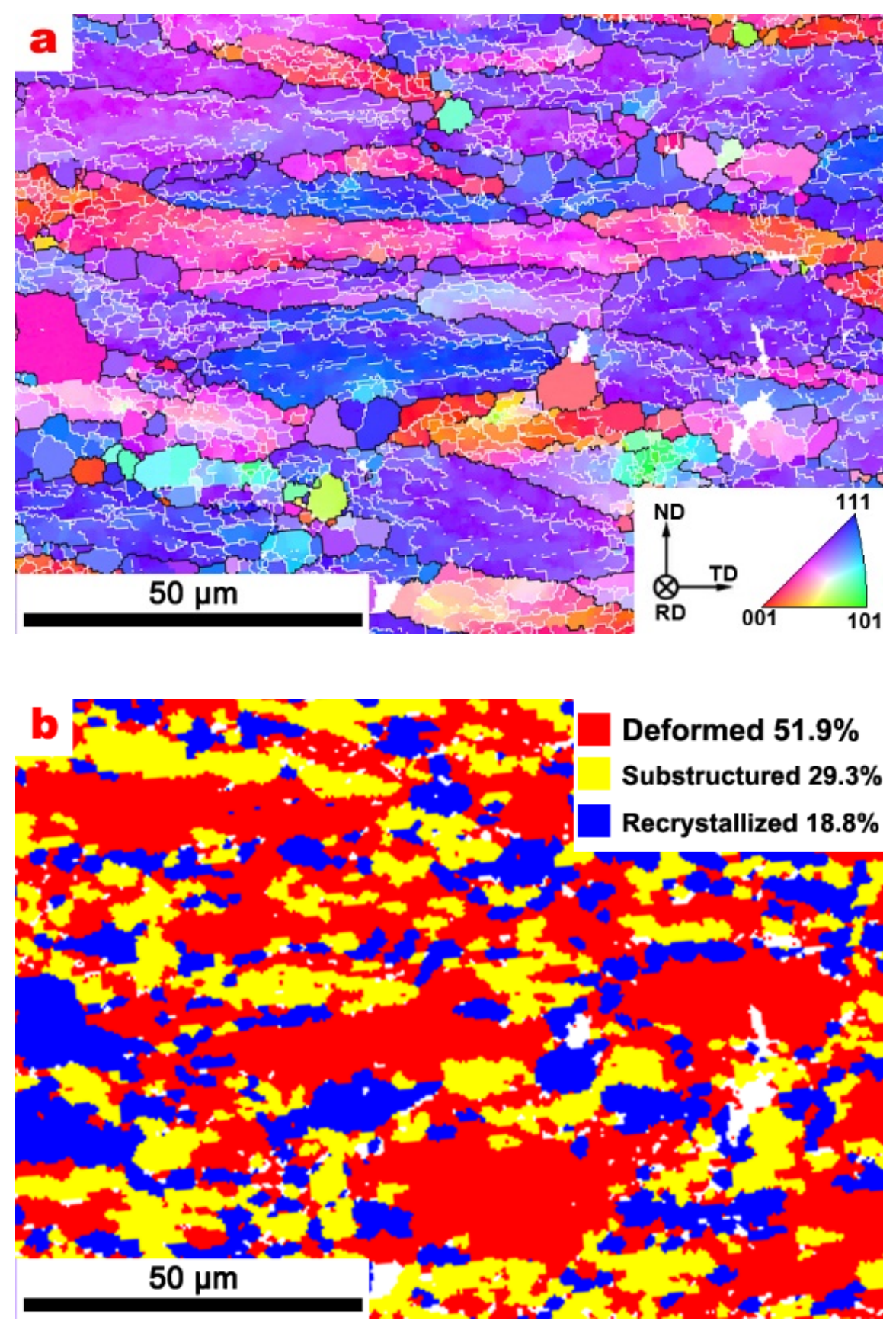

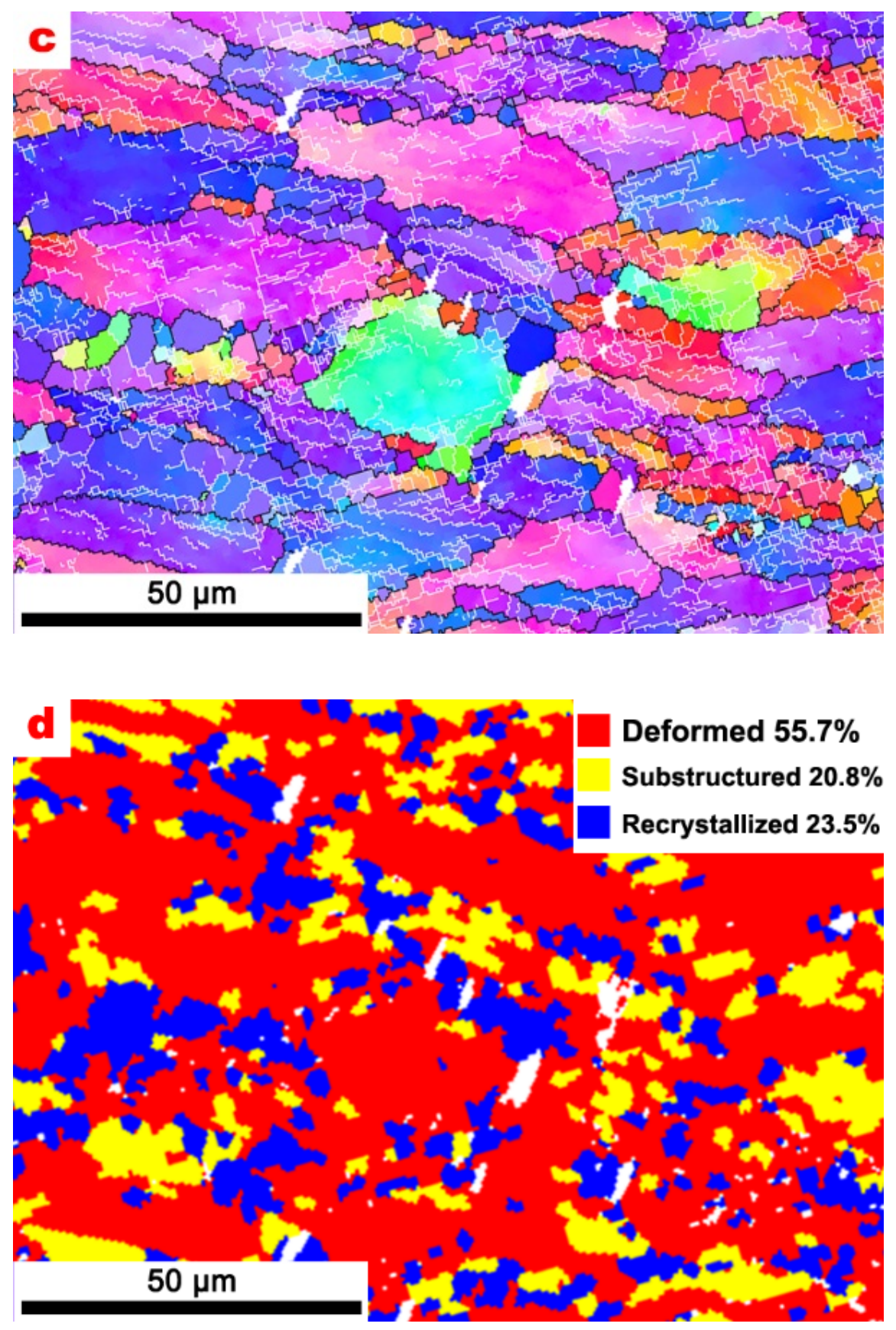

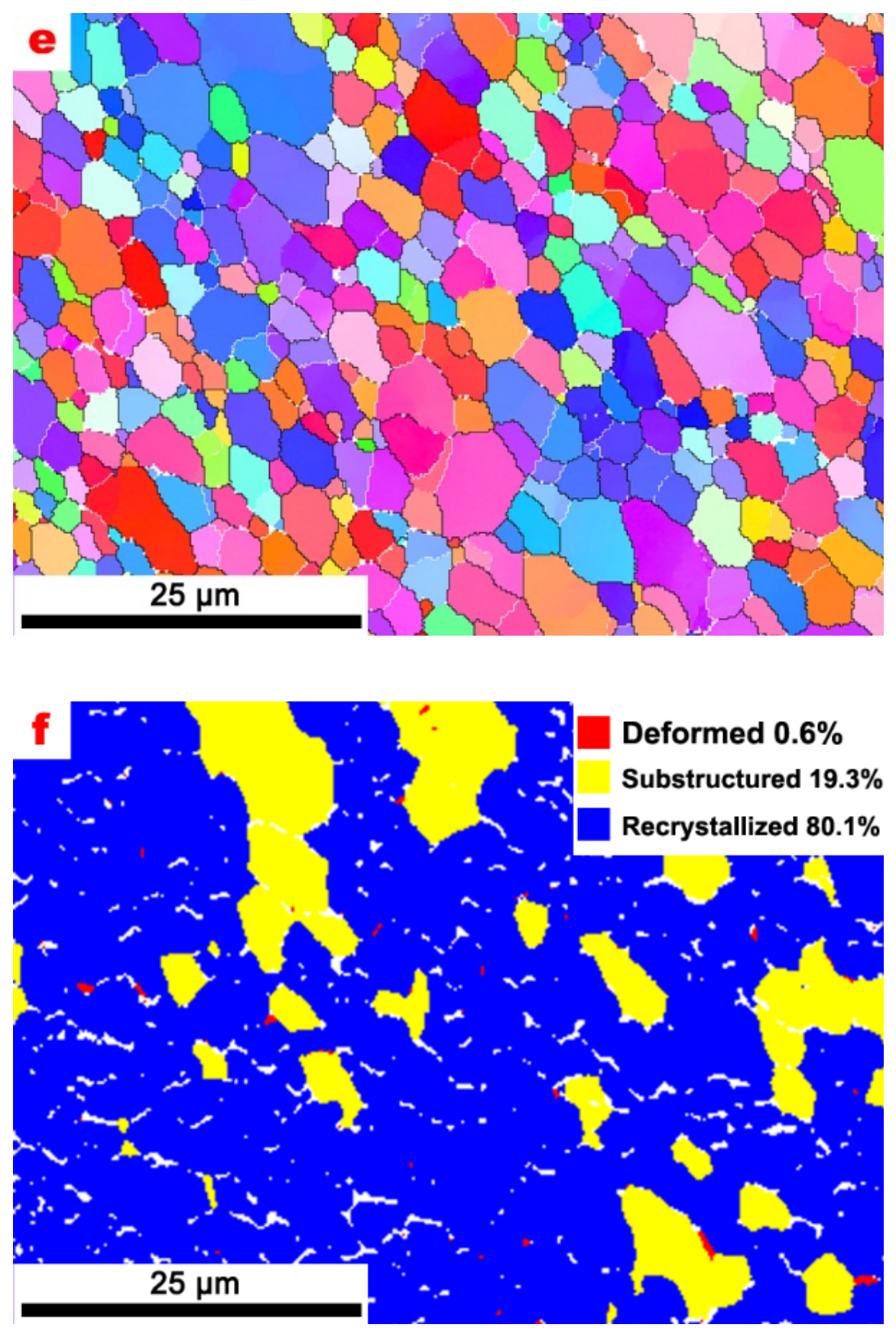

Fig. 6 EBSD misorientation color maps (a, c, e) and corresponding recrystallization results $(\mathrm{b}, \mathrm{d}, \mathrm{f})$ : $(\mathrm{a}, \mathrm{b})$ $\mathrm{BM},(\mathrm{c}, \mathrm{d}) \mathrm{AS}-\mathrm{HAZ},(\mathrm{e}, \mathrm{f}) \mathrm{WNZ}$

According to statistical information estimated by EBSD, the average grain size $\left(\mathrm{d}^{*}\right)$ and misorientation angle were further accurately measured and displayed in Fig. 7. As can be seen that the d* of BM, AS-HAZ were very close, with the values of $14 \mu \mathrm{m}$ and $16 \mu \mathrm{m}$, while the $\mathrm{d}^{*}$ of $\mathrm{WNZ}$ was about $4 \mu \mathrm{m}$ (Fig. 7a). In addition, both BM and AS-HAZ processed high fraction of LAGBs structure, whereas, WNZ mainly consisted of HAGBs recrystallized structure (Fig. 7b). 

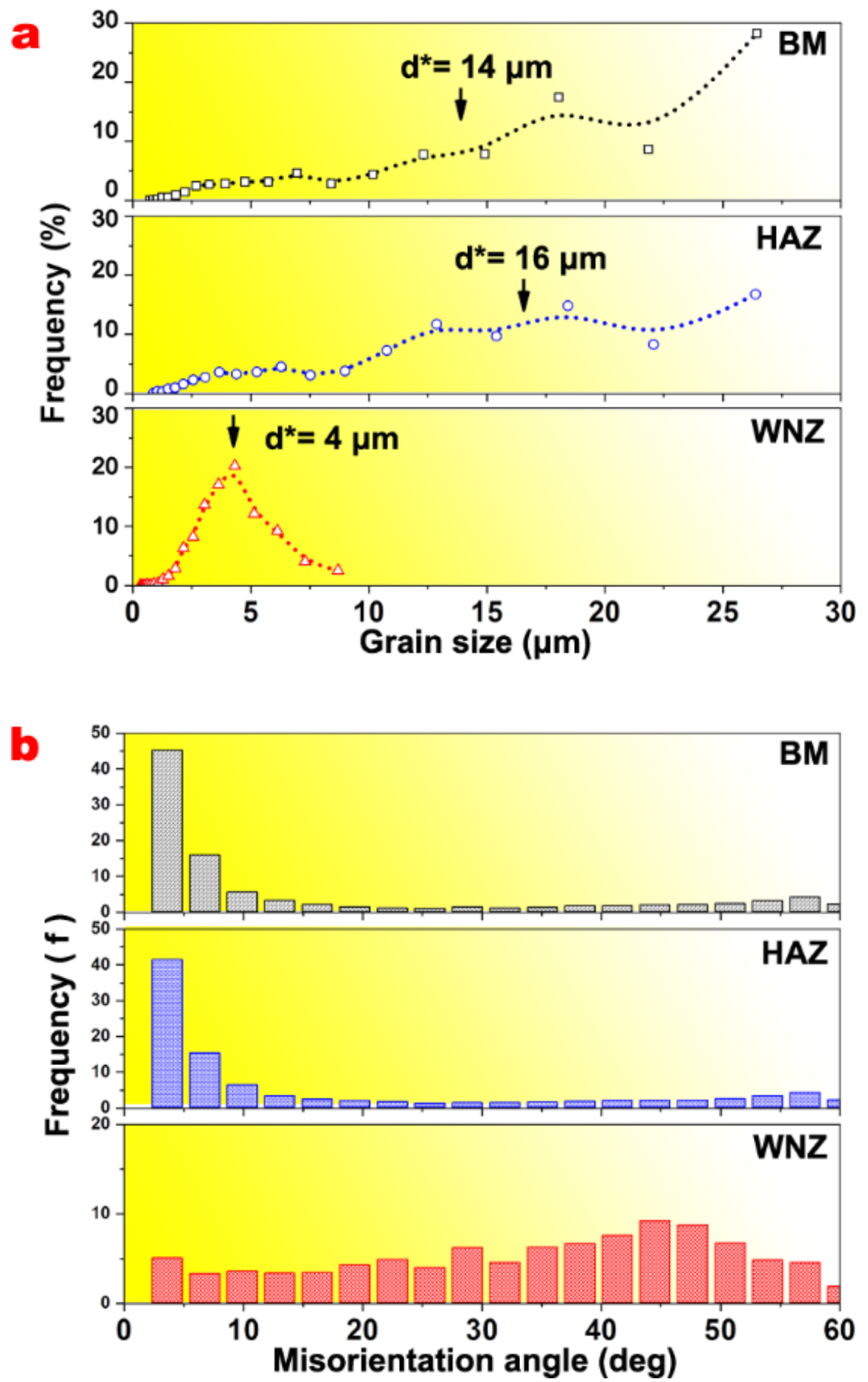

Fig. 7 Grain size (a) and misorientation distributions (b) of BM, AS-HAZ and WNZ samples.

The characteristics of precipitates in BM, AS-HAZ and WNZ were investigated by TEM and HRTEM viewed along with the $\langle 110\rangle_{\text {Al }}$ projection. The results are shown in Fig. 8, Fig. 9 and Fig. 10, respectively. In Fig. $8 \mathrm{a}$, some sub-structures remained in BM after solid solution treatment. Many coherent $\mathrm{Al}_{3}(\mathrm{Sc}, \mathrm{Zr})$ particles with typical Ashby-Brown strain characteristics can be observed in grains, however, the grain boundary 
phase and precipitate-free zone (PFZ) were inconspicuous. At higher magnification, many smaller short rodshaped precipitates could be distinguished clearly in the grains (Fig. 8b). According to the HRTEM images and corresponding inverse fast Fourier transform (FFT) images, one kind of these rod-shaped precipitates precipitated along (11-1) $\mathrm{Al}$ and remained semi-coherent relationship with matrix (framed by rectangle 1), were well accepted as ?' phases [25, 26]. Another kind of smaller precipitates consisted of several atomic layers in thickness and width, and showed fully coherent with the matrix (framed by rectangle 2 and 3 ), were known as GPII zones which often found in Al-Zn-Mg-(Cu) alloys [27, 28]. TEM and HRTEM investigations confirmed that GPII zones and ?' phases were the dominant precipitates in BM.

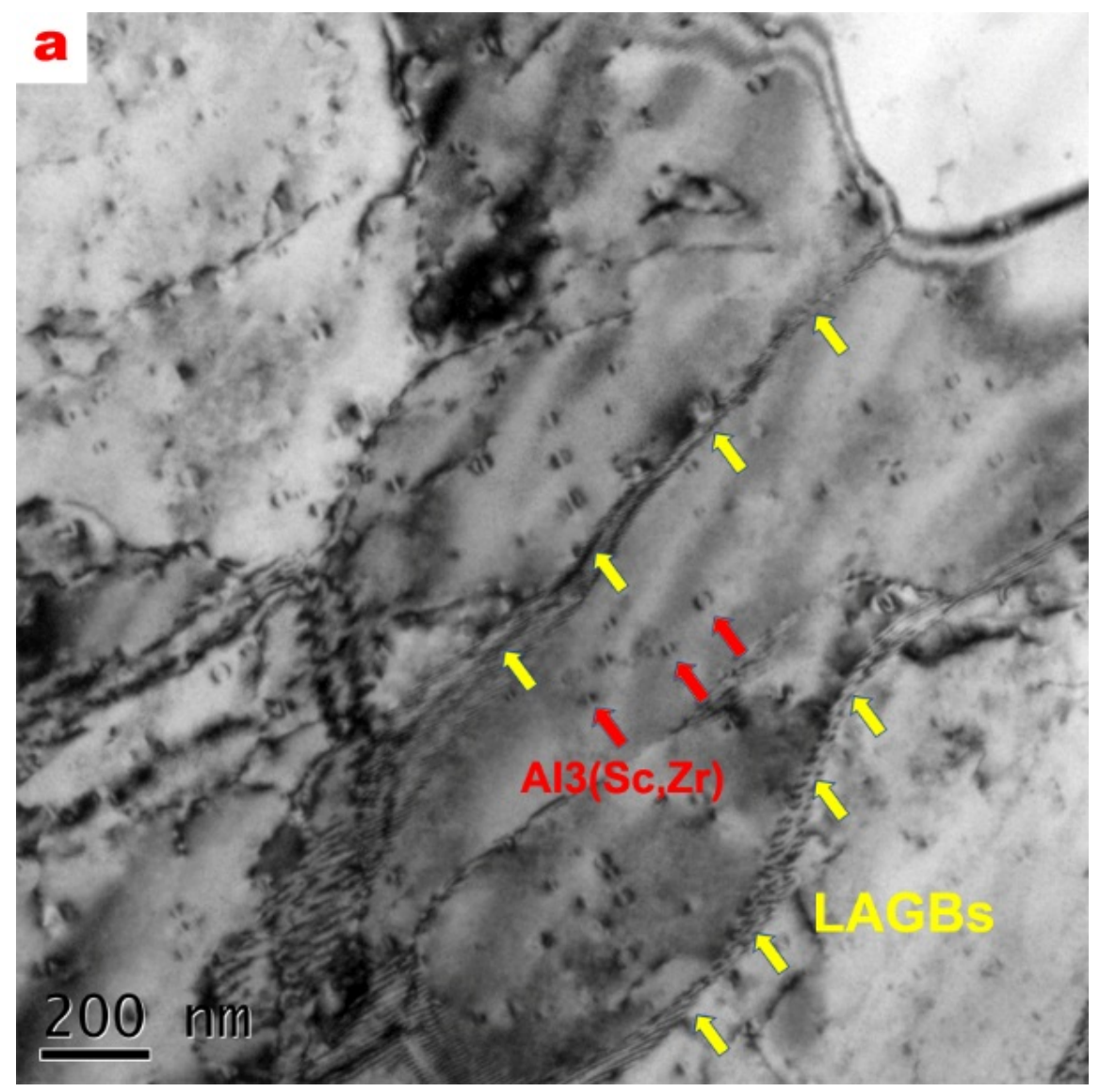




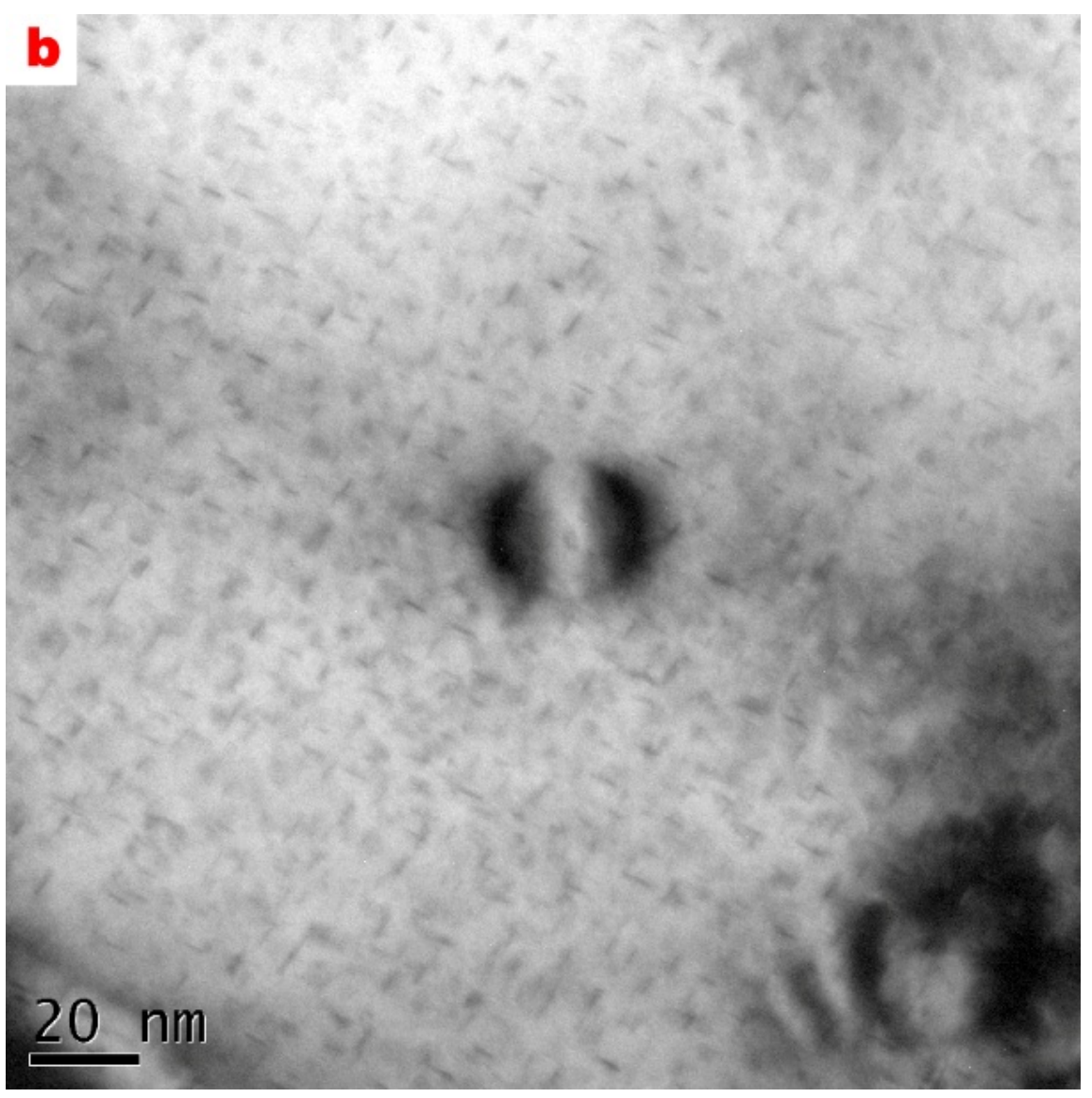




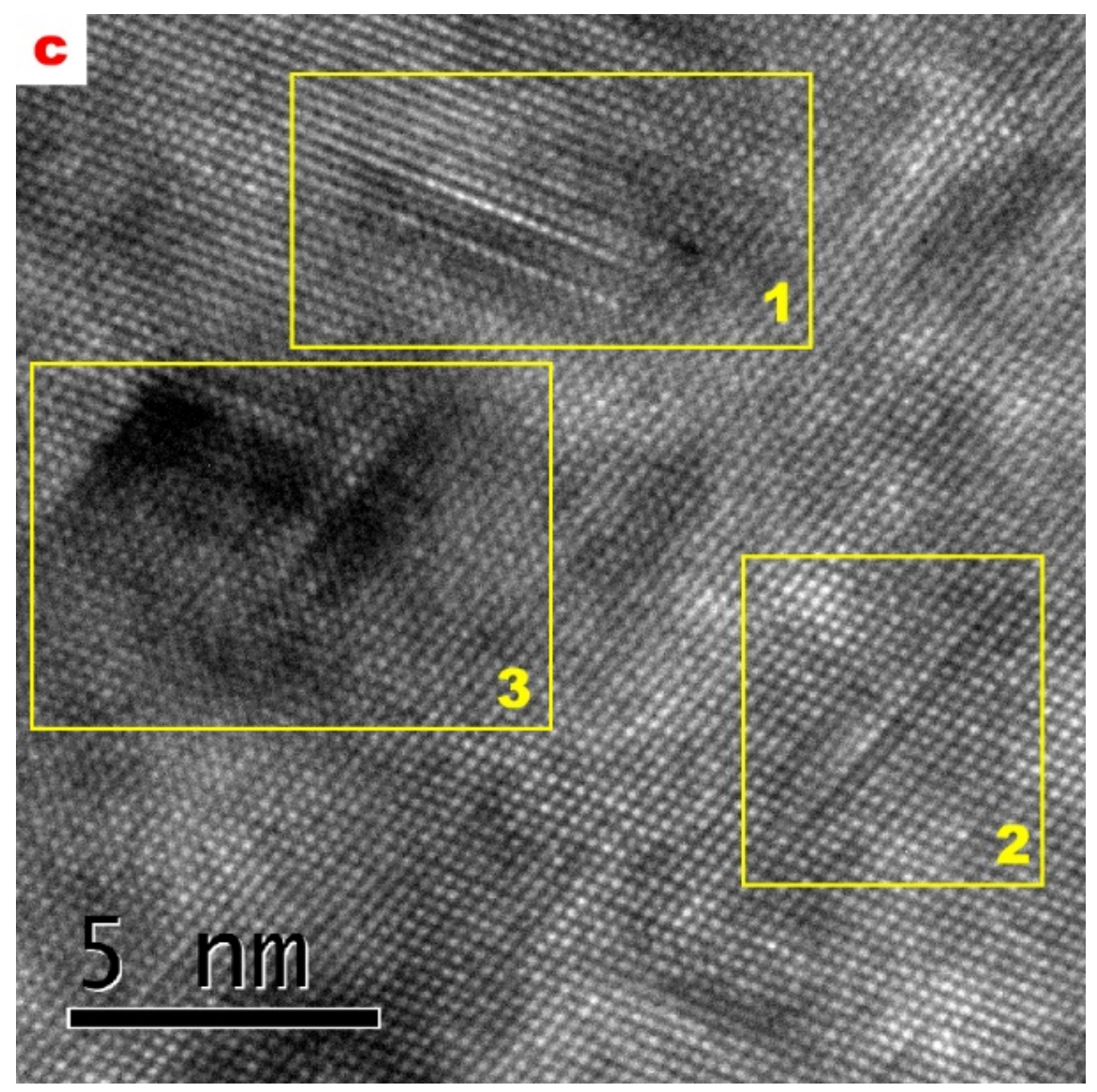



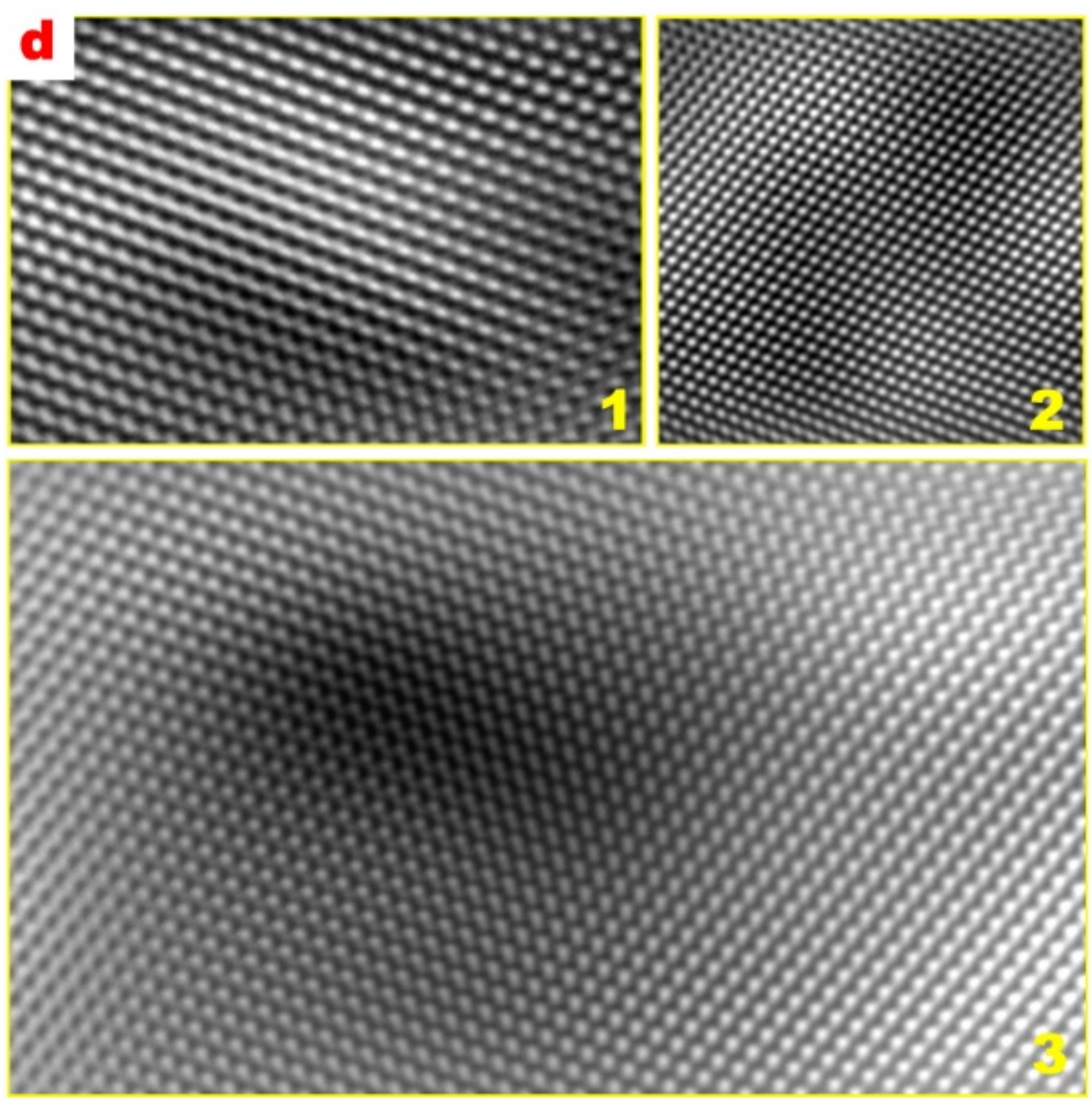

Fig. 8 TEM (a, b) and HRTEM images (c) of matrix precipitates in BM sample. The inverse FFT images after mask to the phases in (c) image are shown in (d).

As shown in Fig. 9a, sub-grains could also be observed in AS-HAZ. Some discontinuous chain-typed ? $\left(\mathrm{MgZn}_{2}\right)$ equilibrium phases formed in grain boundary and the PFZ were obviously observed. As compared with BM, the size of ?' precipitates in grains increased slightly (Fig. 9b). It should be noted that the projections of some precipitates showed short rod-shaped morphology while the others displayed the round morphology, depending on the direction of observation [27]. According to HRTEM observation, all of the ?' precipitates remain semi-coherent relationship with matrix (Fig. 9c and 9d). No clear GPII zones were identified in AS-HAZ. 


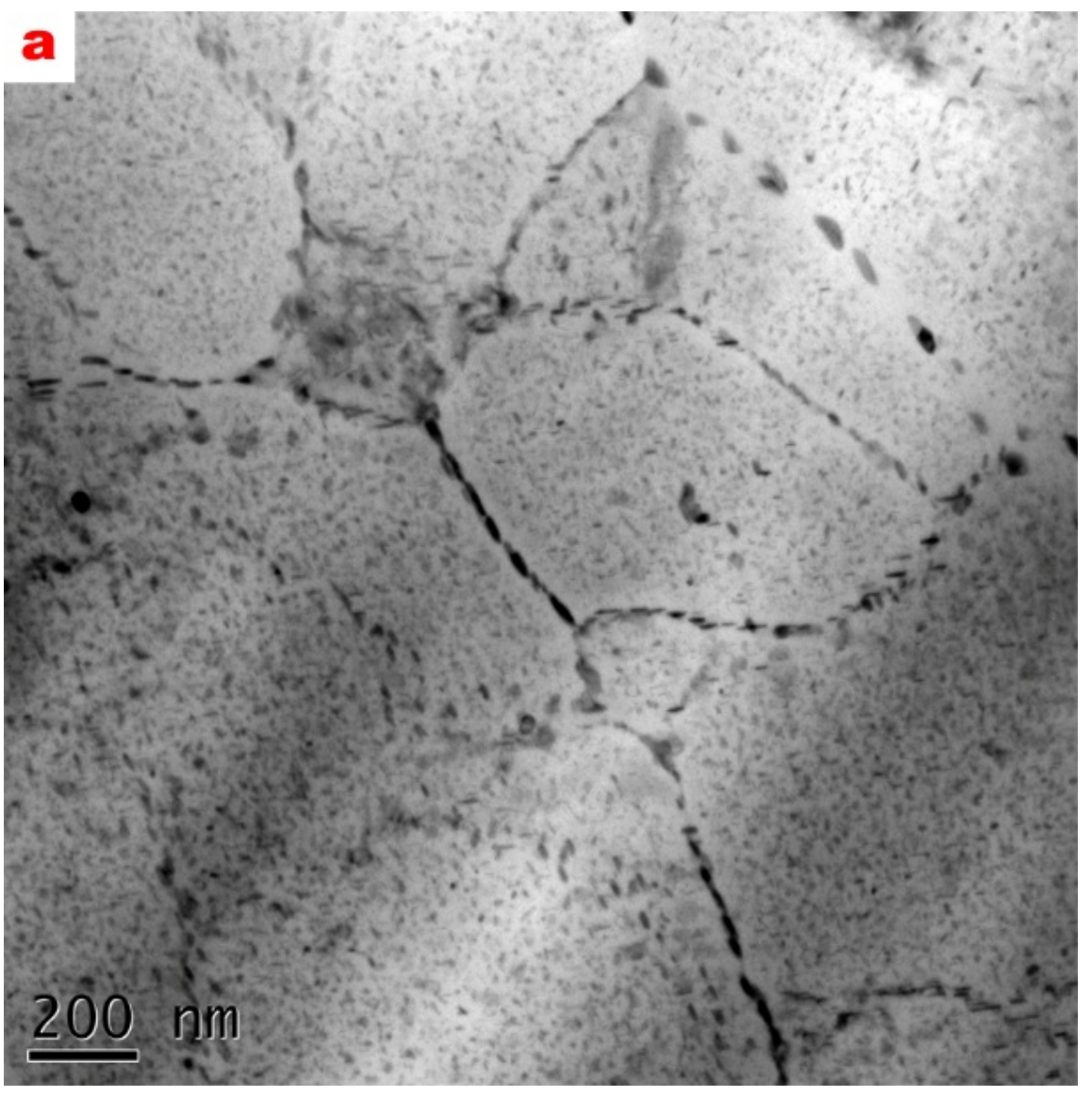




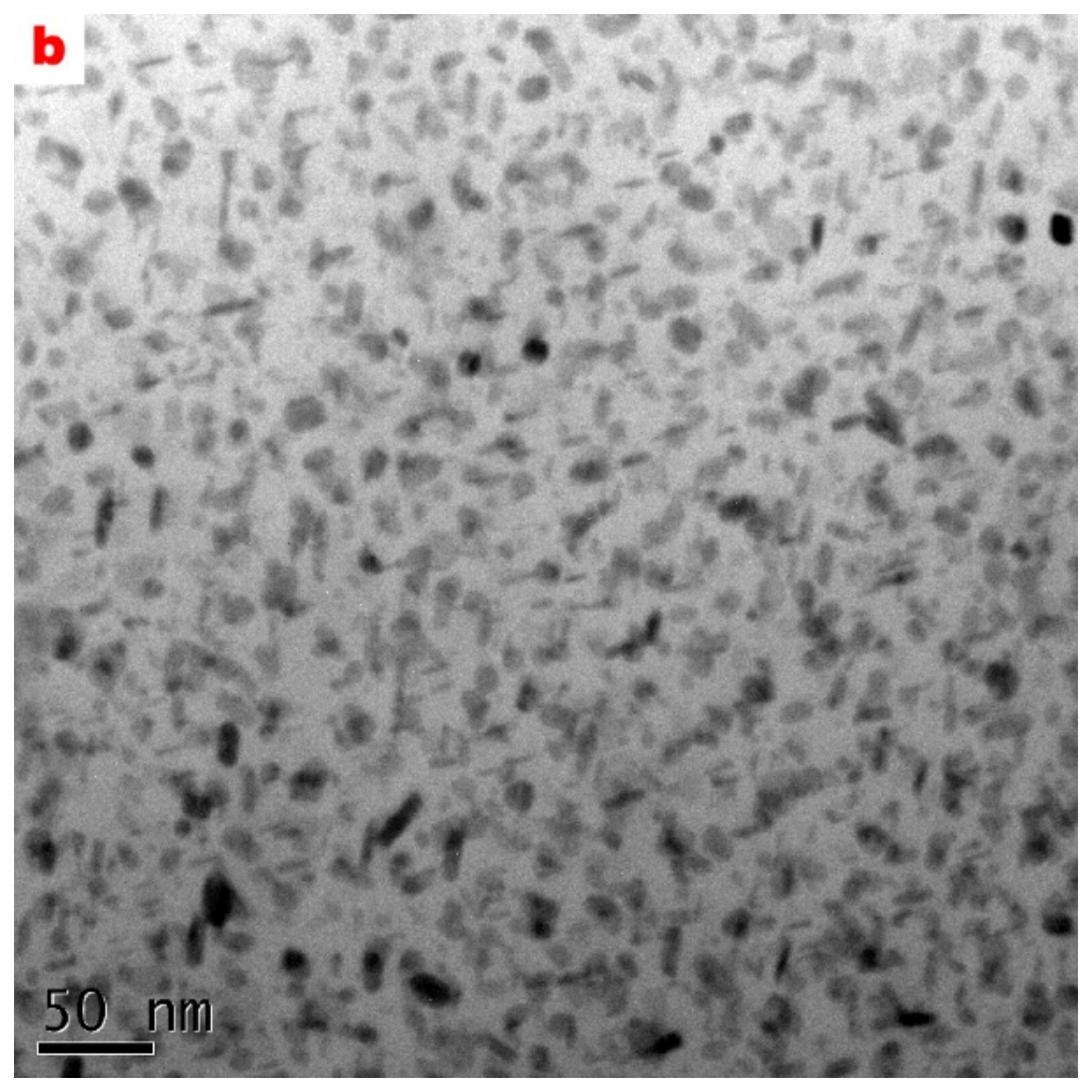




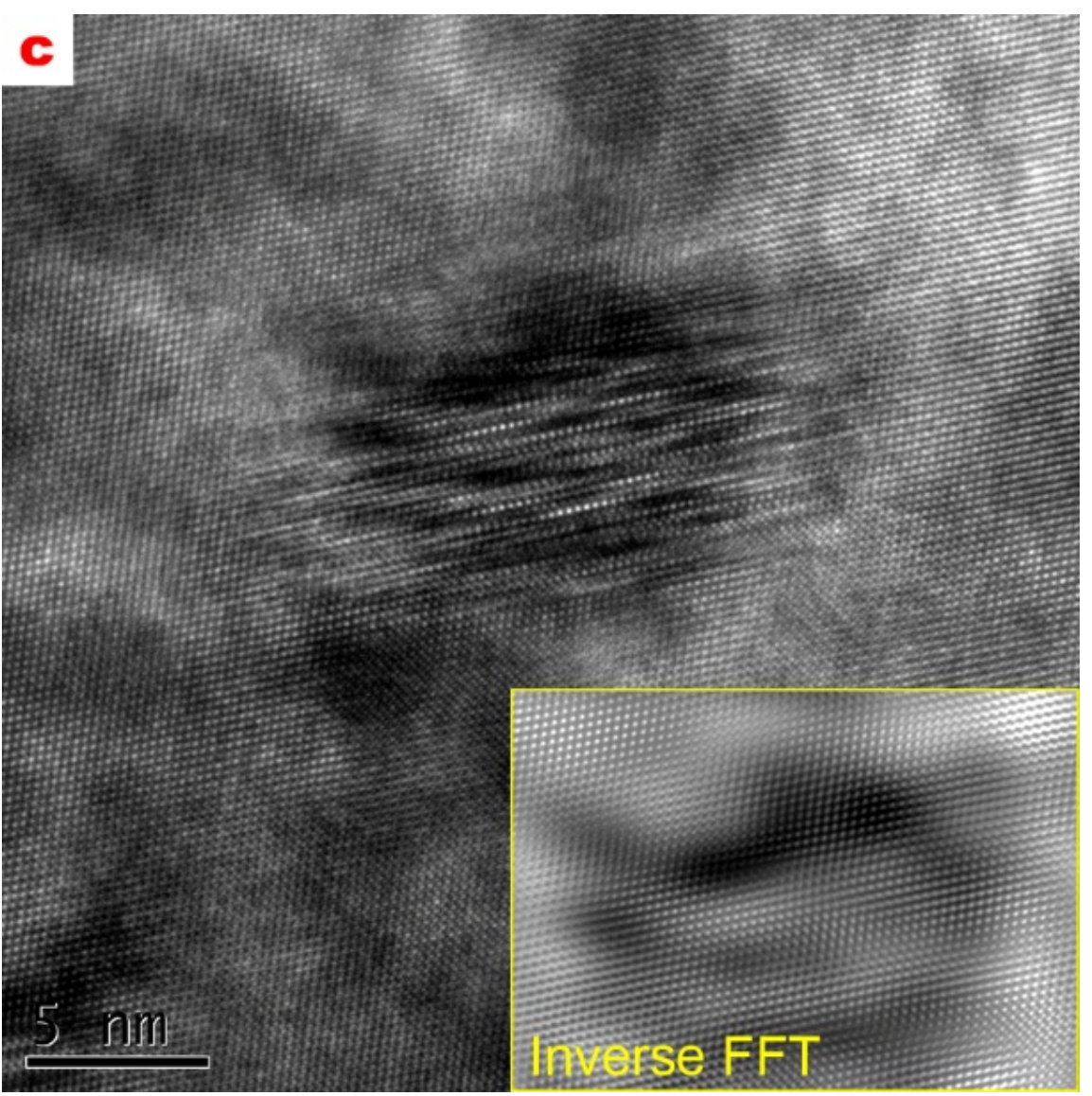




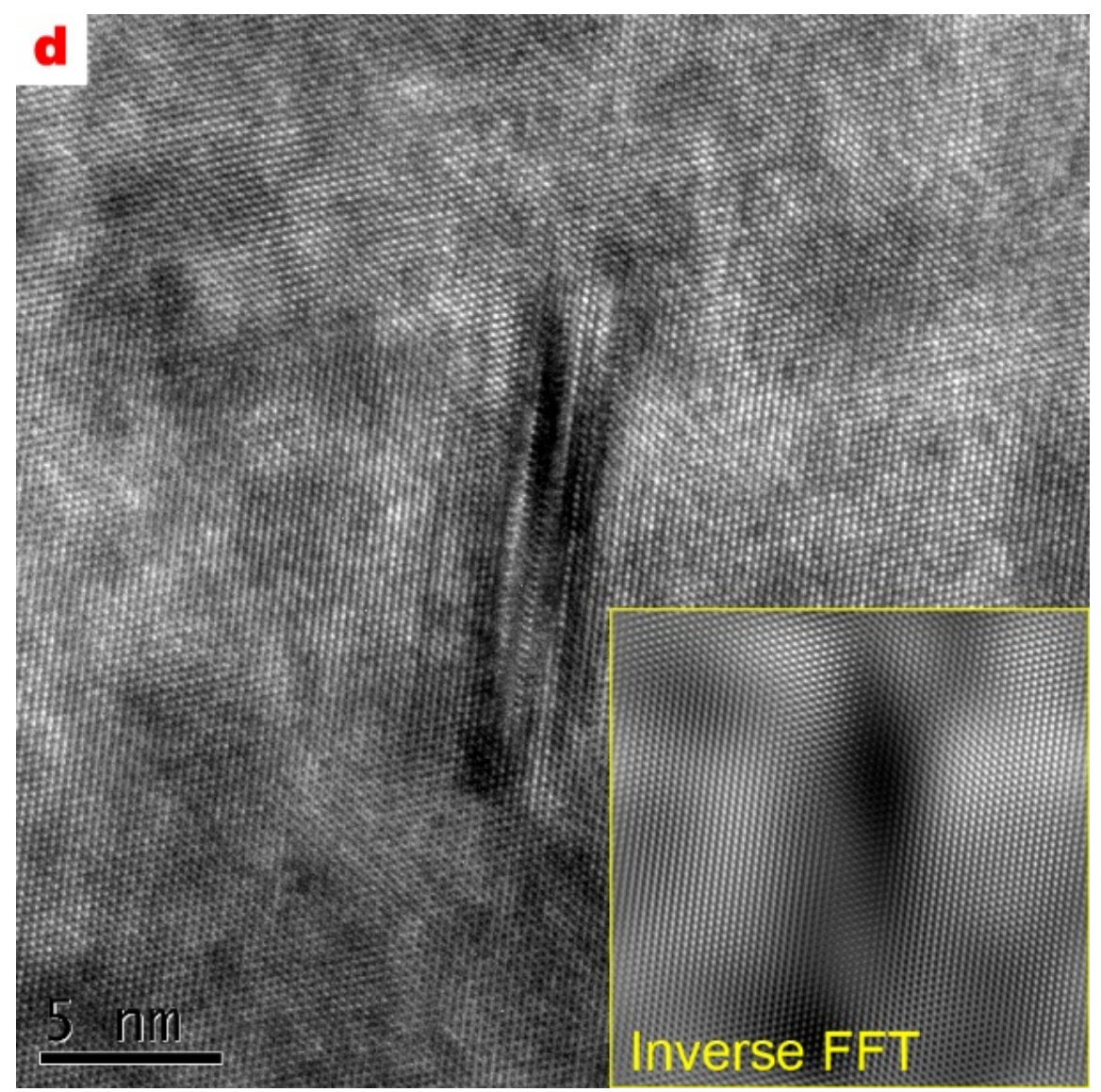

Fig. 9 TEM images (a,b) and HRTEM image (c, d) of matrix precipitates in the AS-HAZ sample.

In WNZ, sub-grains turned to be recrystallized structure due to high weld heat input, and some $\mathrm{Al}_{3}(\mathrm{Sc}, \mathrm{Zr})$ particles grew slightly (Fig. 10a). It is noted that the Ashby-Brown contrasts of the grown $\mathrm{Al}_{3}(\mathrm{Sc}, \mathrm{Zr})$ particles become irregular, indicating that the coherency would be break down during welding. It can be observed that new ? equilibrium phase tended to attach to the grown incoherent $\mathrm{Al}_{3}(\mathrm{Sc}, \mathrm{Zr})$ particles and overgrew. In addition, a considerably amount of nanoscale rod-shaped ?' phase and GPII zones also be observed at higher magnification (Fig. 10b). 


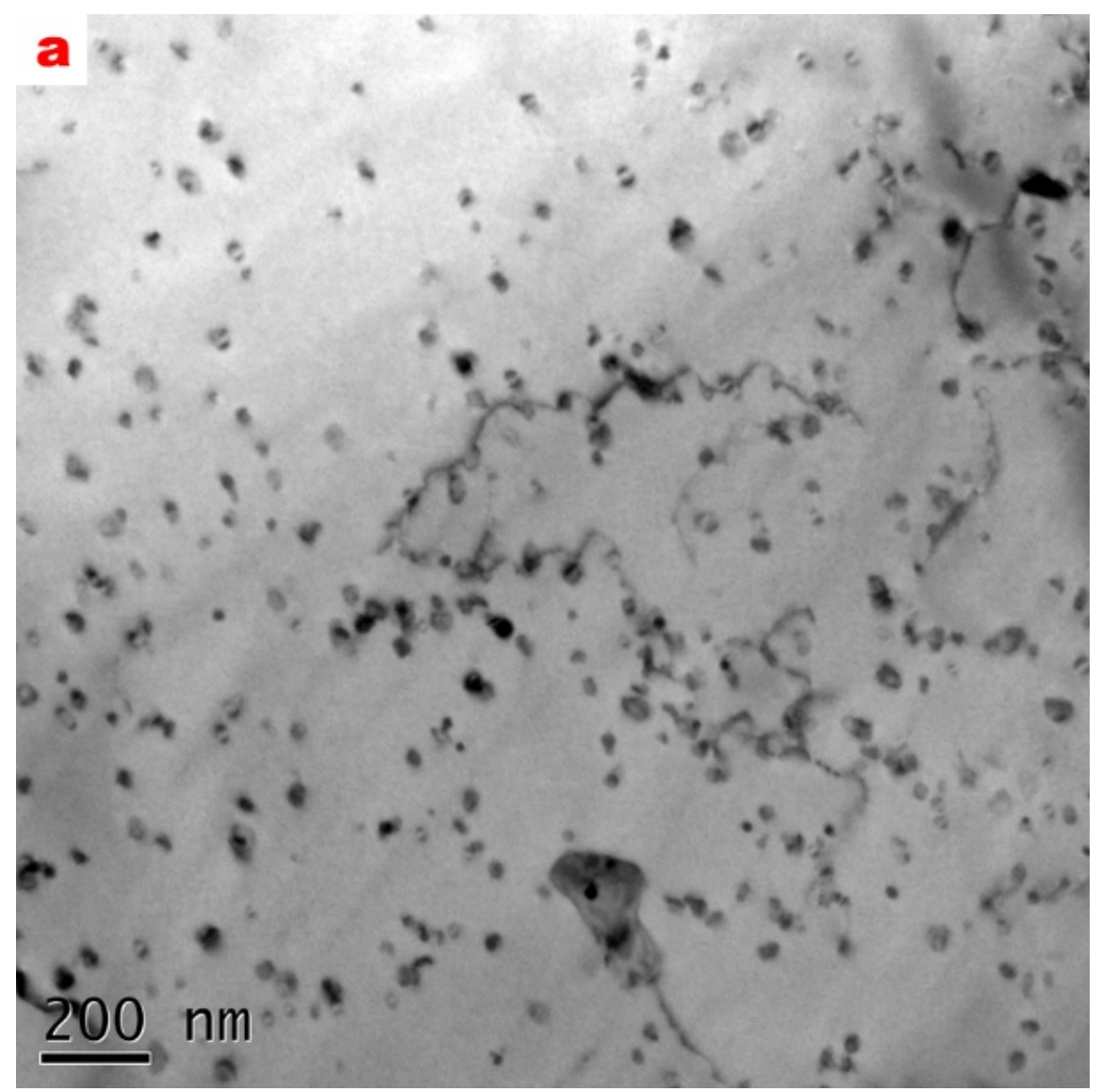




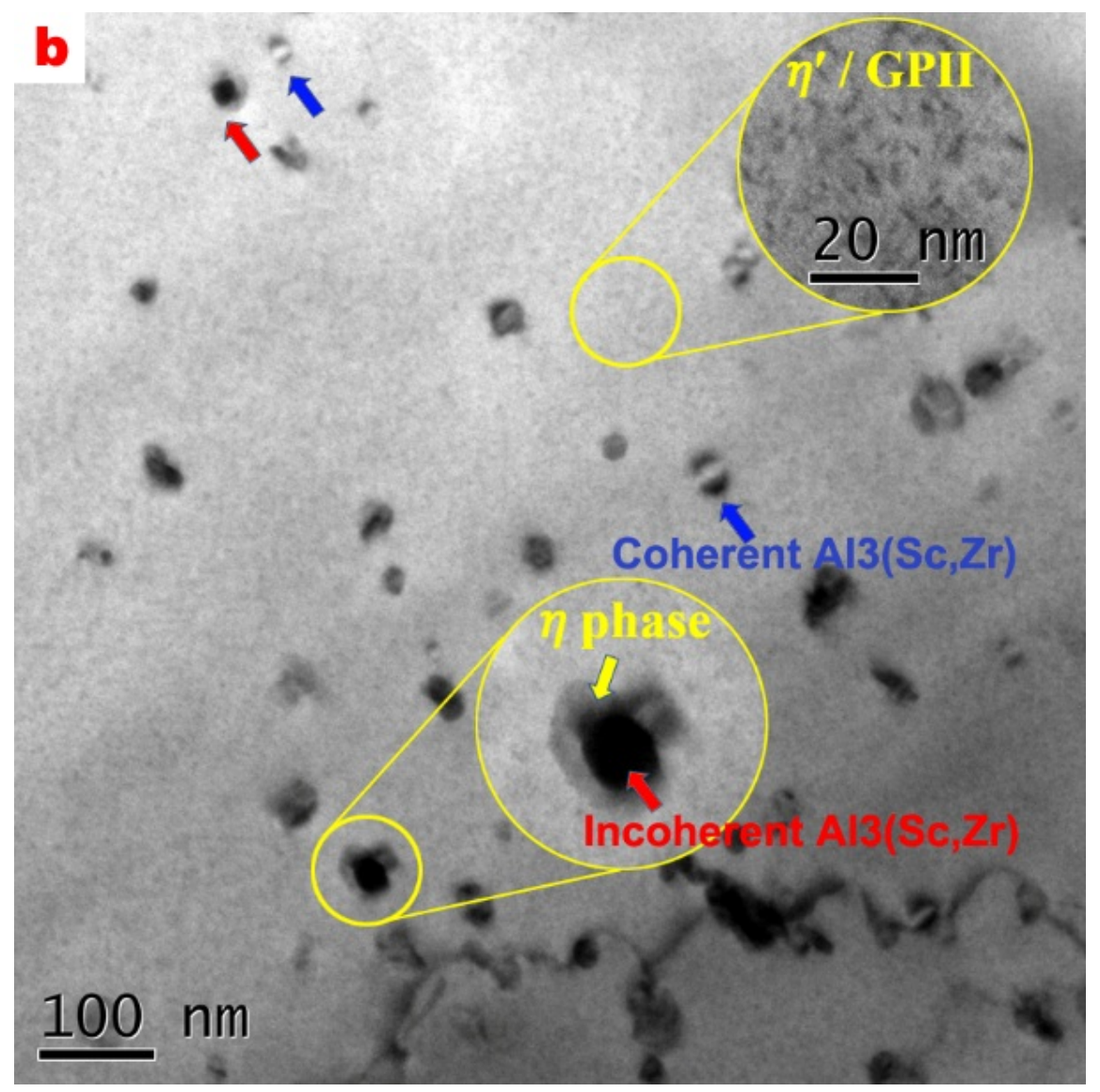

Fig. 10 TEM images of matrix precipitates for the WNZ sample.

\subsection{FCG behavior}

The FCG rate of BM, AS-HAZ and WNZ are shown in Fig. 11. Generally, the curve of FCG consists of three regions, namely, slow crack growth region (I) in low stress intensity factor $(\Delta \mathrm{K})$ range, stable propagation region or Paris regime (II) in medium level range of $\Delta \mathrm{K}$ and rapid propagation region (III) in high range of $\Delta \mathrm{K}$. In present work, the investigated range of $\Delta \mathrm{K}$ was about 7 to $30 \mathrm{MPa} \mathrm{m}{ }^{1 / 2}$. From 7 to $20 \mathrm{MPa} \mathrm{m}^{1 / 2}$, all samples showed approximate linear dependency of $\Delta \mathrm{K}$ on the FCG rate, indicated characteristic of Paris regime (II). In this region, BM sample presented a consistently higher FCG rate as compared with AS-HAZ and WNZ. The FCG rate of AS-HAZ rose faster than WNZ with increasing of $\Delta \mathrm{K}$. When $\Delta \mathrm{K}$ exceeded 20 $\mathrm{MPa} \mathrm{m}^{1 / 2}$, a noticeable change in the slope of the curve was observed, indicating that crack growth was entering into the rapid propagation region (III). In this region, the FCG rate of BM and AS-HAZ was close, much higher than that of WNZ. 


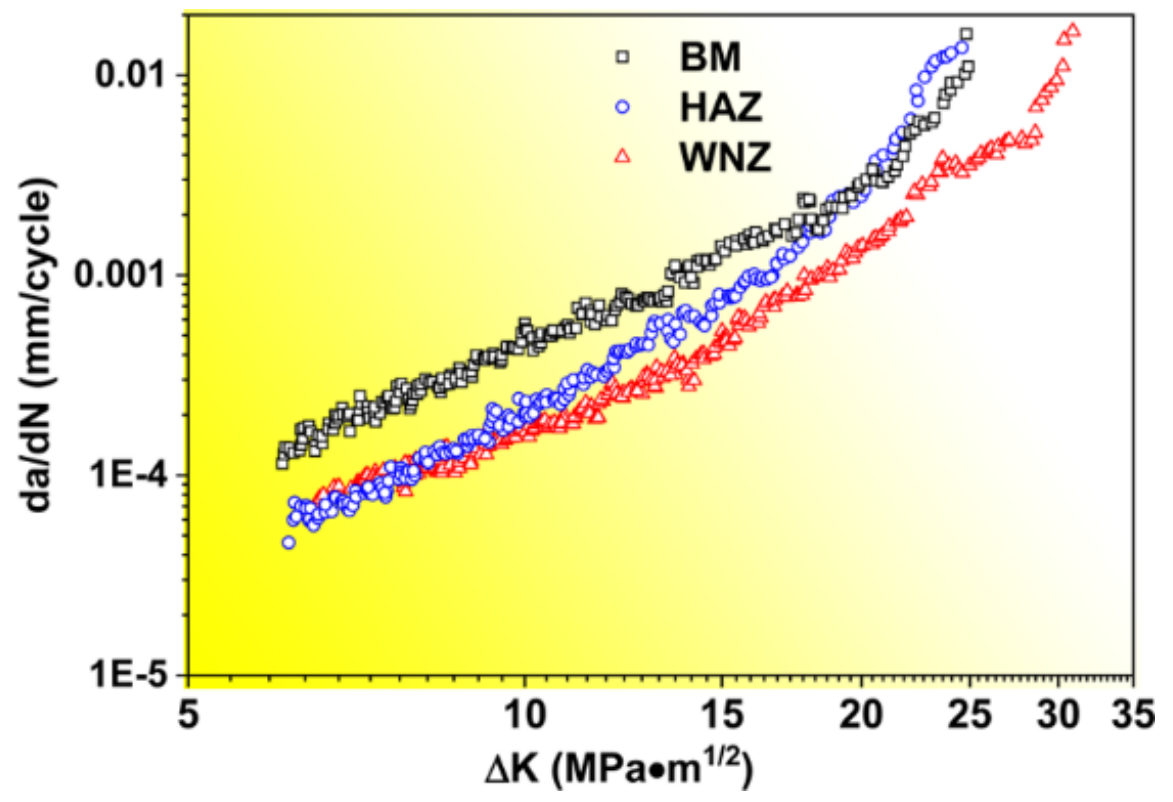

Fig. 11 Relationship of FCG rate and the stress intensity factor range of BM, AS-HAZ and WNZ.

3.4. Morphological features of fracture surface Fig. 12 shows the typical SEM fractographs of fatigue fracture features at stable propagation $\left(\Delta \mathrm{K}=15 \mathrm{MPa} \mathrm{m}^{1 / 2}\right)$ region. From the fracture surfaces of BM and AS-HAZ, it can be seen that obvious tearing ridges distributed along the propagation direction, tearing dimples and small-scale facets formed during crack propagation. Some coarse intermediate Fe-containing particles which usually formed during casting were found in tearing dimples (Fig. 12a). At higher magnification, fatigue striations on the facets can be observed clearly. The characteristic fatigue fracture features of BM and AS-HAZ were substantially similar but with two notable differences. Firstly, the amount of tearing ridge on the fracture surface of AS-HAZ was fewer than BM while the tearing dimples were more numerous. Secondly, the average spacing of fatigue striations in AS-HAZ was smaller than BM, the statistics average values were $1.5 \mu \mathrm{m}$ and $1 \mu \mathrm{m}$, respectively. By contrast, the fatigue fracture features of WNZ were quite different. The tearing ridges turned to be smaller and not distributed strictly parallel to the direction of propagation, and the amount of shallow tearing dimples increased significantly. Large size intermediate particles were probably broken down by pin tool during welding, therefore coarse Fe-containing phases were scarcely observed in WNZ (Fig. 12e). It is noted that many second cracks and facets with smaller scale formed on the fracture surface of WNZ, the spacing of fatigue striation became indistinguishable attributed to the existence of second cracks. These fracture features revealed that the crack path of WNZ would be more tortuous and in favor to slower FCG rate as compared with BM and AS-HAZ. Fig. 12 SEM micrograph of fatigue fracture surfaces at the stage of stable expanding region for BM, AS-HAZ and WNZ specimens.

\section{Discussion}

\subsection{Effect of Sc on microstructure and mechanical properties}

Significant recrystallization suppression effect of Sc addition in aluminium alloys has been previously shown to arise from the precipitation of second $\mathrm{Al}_{3}(\mathrm{Sc}, \mathrm{Zr})$ particles formed during homogenization thermal treatment $[16,29]$. In $7085 \mathrm{Sc}$ alloy, $\mathrm{Al}_{3}(\mathrm{Sc}, \mathrm{Zr})$ particles formed in the matrix and inhibited recrystallization during hot-rolled deformation as well as solution treatment. Therefore, noticeable sub-grains remained in BM and produced strengthening (Fig. 6 and Fig. 8a). Owing to sub-grains strengthening and precipitation strengthening of GPII zones as well as ?' phases, the UTS of 7085Sc-T6 increased to $593 \mathrm{MPa}$ which was higher than AA7085-T6 reported in Ref. [30].

The welding behaviors of $7085 \mathrm{Sc}$ alloy was also affected by $\mathrm{Al}_{3}(\mathrm{Sc}, \mathrm{Zr})$ particles. It is known that grain growth 
and dissolution/coarsening of hardening phases tend to occur when suffered high FSW heat input, resulting significant softening in welded joint of heat-treatable strengthening Al alloys [24, 31]. For the studied 7085Sc FSWed joint, sub-grains in AS-HAZ did not grew during FSW because the migration of grain boundaries were retarded by $\mathrm{Al}_{3}(\mathrm{Sc}, \mathrm{Zr})$ particles (Fig. 6 and Fig. 7). Therefore, the presence of $\mathrm{Al}_{3}(\mathrm{Sc}, \mathrm{Zr})$ particles had significant benefit to decrease the strengthening degradation in HAZ. The softening bands in HAZ of 7085Sc FSWed joint could be mainly attributed to dissolution of coherent GPII and growth of semi-coherent metastable ?' phases (Fig. 9), similar to the previous reports [32, 33].

As compared with HAZ, WNZ showed higher hardness and better tensile properties (Fig. 3 and Fig. 4). One reason would be the high strengthening of finer grain structure. It is known that high friction heat input during FSW process would induce recrystallization and grain growth in WNZ. For the 7085Sc alloy, grain growth was restrained in WNZ due to high recrystallization resistance of the thermally stable $\mathrm{Al}_{3}(\mathrm{Sc}, \mathrm{Zr})$ particles (Fig. 7). Another main reason would be the strengthening of reprecipitated hardening phases. It has estimated that the temperature in $\mathrm{WNZ}$ would be above $500^{\circ} \mathrm{C}$ [34], redissolution of precipitated phases would occur in this condition and a supersaturated solid solution would form in WNZ during subsequent air-cooling process. Similar to the slow quenching process of Al-Zn-Mg-Cu alloys [35], the supersaturated solid solution in WNZ tended to decompose after welding, forming overgrowth quench-induced equilibrium phases and nanoscale precipitates. It has been proved that? equilibrium phases as the result of heterogeneous precipitation appear to be mostly nucleated on pre-existing incoherent $\mathrm{Cr}$ or $\mathrm{Zr}$-containing dispersoids in slow quench processing of $\mathrm{Al}-\mathrm{Zn}-\mathrm{Mg}$-Cu alloys $[21,36]$. For $7085 \mathrm{Sc}$ alloy, $\mathrm{Zr}$-containing dispersoids in the matrix were mainly $\mathrm{Al}_{3}(\mathrm{Sc}, \mathrm{Zr})$, thus, the decomposition process of the supersaturated solid solution in WNZ would be associated with $\mathrm{Al}_{3}(\mathrm{Sc}, \mathrm{Zr})$ particles. As TEM observation showed that just a few $\mathrm{Al}_{3}(\mathrm{Sc}, \mathrm{Zr})$ particles coarsened and lost coherency when suffered the complicated thermo-mechanical input of FSW, more coherent $\mathrm{Al}_{3}(\mathrm{Sc}, \mathrm{Zr})$ particles retained in WNZ after welding (Fig. 10). Because coherent particles were able to reduce heterogeneous precipitation of overgrowth ? phases by preventing the spread of voids [37], only a small amount of incoherent $\mathrm{Al}_{3}(\mathrm{Sc}, \mathrm{Zr})$ particles acted as nucleate of ? equilibrium phases. Therefore, the formation of? equilibrium phases in WNZ was restrained, instead, many $\mathrm{Zn}$ and $\mathrm{Mg}$ solutes in the solid solution tended to reprecipitate in form of ?' and GPII as observed in Ref. [38]. Consequently, mass of homogeneous fine hardening precipitates could be obtained in WNZ, resulting improvement of hardness, YS and UTS values.

\subsection{FCG behavior of welding joint}

In current study, it was found that significant inhomogeneity of FCG rate existed in different regions of 7085Sc FSWed joint (Fig. 11). As widely known that FCG behavior is significantly associated with the microstructure of alloys. For heat-treatable alloys, previous works have proved that grain structure and hardening phases are the main microstructure factors on FCG rate [31, 39, 40]. The BESD analysis and TEM observation shown in Fig. 6 and Fig. 7 revealed that the grain structures in BM and AS-HAZ were approximately similar, while the morphology of hardening phases in these two regions were quite different (Fig. 8 and Fig. 9). Thus, it can be reasonably concluded that the difference of FCG behavior between BM and AS-HAZ was mainly induced by hardening phases, while the effect of grain structure could be negligible. As compared with BM/AS-HAZ, grain structure and hardening phases in WNZ had more distinctive characteristic, therefore, the effects of both two factors on the FCG behavior should be highlighted. According to early researches $[25,31,41,42]$, hardening phases played a noticeable role to intervene FCG process by interaction between dislocations. During the FCG process, dislocation nucleation and movement were promoted at the crack tip, undoubtedly, the interaction between hardening phase and movable dislocation turn to be frequent in this region. For coherent or semi-coherent phase, dislocation could shear it and glide reversibly with in a persistent slip band during cyclic loading. This kind of kinematical reversibility of cyclic slip would lead to a more deflective, tortuous and bifurcate fatigue crack path as well as inhomogeneous deformation on the crack tip, contributing to enhancement of FCG resistance. On the contrary, dislocation tends to bypass non-coherent phases rather than shear. In this situation, irreversible deformation turns to be dominated and increased damage accumulation on the crack tip, and finally degrade the FCG resistance. It should be noted that whether in shear or bypass mechanism, the radius $(r)$ and the volume fraction $(f)$ 
of hardening phases are two important microstructural parameters. Wen et al. [25] summarized and proposed succinct equations to express the relationship as listed below: shear mechanism: $\frac{\mathrm{da}}{\mathrm{dN}} \propto(r \bullet f)^{-1 / 2}(1)$ bypass mechanism: $\frac{\mathrm{da}}{\mathrm{dN}} \propto r \bullet f^{-1 / 2}$ (2) Obviously, the FCG rate is negatively related to $r$ and $f$ of shearable precipitates according to Eq. (1), and the FCG rate is positively related to $r$ of non-shearable precipitates while negatively related to its faccording to Eq. (2). These relationships can be used to explain the FCG inhomogeneity of 7085Sc FSWed joint. As can be seen from TEM images, the dominated hardening phases in both BM and AS-HAZ samples consisted mostly of coherent GPII and semi-coherent ?', indicating that shear mechanism was the main interaction mode in these two regions during cyclic loading. However, the average size and volume fraction of precipitates in AS-HAZ are much higher than that of BM. According to Eq. (1), the FCG resistant of AS-HAZ should theoretically be higher than BM. This theoretical deduction is entirely consistent with experimental data shown in Fig. 11. For WNZ sample, precipitates in matrix consisted of a considerably amount of reprecipitated coherent phase (?' and GPII) as well as some coarse non-coherent phase (?). According to shear mechanism mentioned above, high volume fraction of coherent phases would be beneficial to enhancement of FCG resistance. The supporting evidences could be found in Bray's work demonstrating that naturally aged $\mathrm{Al}-\mathrm{Cu}-\mathrm{Mg}$ alloys had excellent fatigue properties [41]. According to Eq. (2), bypass mechanism of ? phases with large $r$ and low $f$ in WNZ also contributed to reduction of FCG rate. In addition to the effects of precipitates, another considerable factor on FCG rate of WNZ is the grain structure. It has been known that due to small angle of preferential slip planes between adjacent grains, fatigue crack tends to expand across multiple grains at a time in alloy with high texture intensities, resulting low FCG resistance [43, 44]. As compared with BM and AS-HAZ, WNZ possessed recrystallized grains with smaller size and random crystal orientation (Fig. 6 and 7), in this situation, a higher force was required for the propagation of fatigue crack as the impeding effect caused by high angle grain boundary. Therefore, the deflection, torsion and bifurcation of fatigue crack occurred more frequently (Fig. 12), leading to a significant decrease of FCG rate. Due to the combined effects of precipitates and grain structures, FCG property of WNZ was better than other welding regions as well as BM. In addition, the influence of grains structure on FCG is associated with the cyclic plastic zone (CPZ) at the crack tip [25]. The CPZ size could be estimated by $\delta_{f}=\frac{1}{8 \pi}\left(\frac{K}{\sigma_{y}}\right)^{2}$, here $\left(\sigma_{\mathrm{y}}\right)$ accurately would be the strength of the plastic zones near the fatigue crack tip. Obviously, the CPZ rises with increasing of $\Delta \mathrm{K}$. When CPZ size is larger than a grain scale, the effects of grain structure on the FCG would turn to be dominant [45]. Because $\mathrm{BM}$ and AS-HAZ processed similar grain structure, thus, the crack in BM and AS-HAZ samples showed roughly the same FCG rate at high $\Delta \mathrm{K}\left(>20 \mathrm{MPa} \mathrm{m}^{1 / 2}\right)$.

\section{Conclusions}

The inhomogeneity of microstructure, hardness, tensile properties and FCG behavior of 7085Sc FSW weld joint was investigated and discussed. Based on the experimental results, the following major conclusions can be drawn:

(1) The recrystallization resistance of the $7085 \mathrm{Sc}$ alloy was improved by coherent $\mathrm{Al}_{3}(\mathrm{Sc}, \mathrm{Zr})$ particles, thus, sub-grains were remained in BM after solution treatment and the grain growth was inhibited in AS-HAZ during FSW process. Frictional heating and intense plastic deformation caused fined recrystallized grains formed in WNZ, the average grain size was $4 \mu \mathrm{m}$, smaller than that of BM $(14 \mu \mathrm{m})$ and AS-HAZ $(16 \mu \mathrm{m})$.

(2) FSW heat input induced dissolution of GPII and slightly growth of metastable phases ?' in AS-HAZ, by contrast, completely redissolution of hardening precipitates occurred in WNZ forming supersaturated solid solution which tend to decompose to form new reprecipitated GPII, ?' and ? phases after FSW. However, the heterogeneous precipitation of overgrowth ? phases were reduced by coherent $\mathrm{Al}_{3}(\mathrm{Sc}, \mathrm{Zr})$ particles. Owing to precipitation strengthening and fine grain strengthening, the tensile properties of WNZ (UTS: 330MPa and YS: $485 \mathrm{MPa}$ ) were higher than that of AS-HAZ (UTS: 415MPa and YS:262MPa).

(3) The FCG rate of AS-HAZ was lower than BM in Paris regime because the FCG resistance in HAZ was improved by slight grew semi-coherent ?' as shear mechanism. However, the FCG rates of BM and AS-HAZ were close at high $\Delta \mathrm{K}$ due to the similar grain structures. WNZ possessed the best fatigue endurance because 
of shear mechanism of reprecipitated coherent phases (GPII and ?') and bypass mechanism of ? phases with large size and low volume fraction. Moreover, fine recrystallized grains with random crystal orientation in WNZ also contributed to reduction of FCG rate. The combined effects of precipitates and grain structures induced frequent deflection, torsion and bifurcation of fatigue crack, resulting in significant reduction of FCG rate in $\mathrm{WNZ}$.

\section{CRediT authorship contribution statement}

Zixing Jia: Methodology, Investigation, Writing - original draft. Lili Wei: Funding acquisition, Writing review \& editing. Hongfeng Huang: Funding acquisition, Validation.Chongyu Liu: Conceptualization, Supervision. Hongjie Jiang: Methodology, Investigation. Xuda Xu: Resources.

\section{Acknowledgments}

This work was funded by the Natural Science Foundation of Guangxi (grant no.2018GXNSFAA138065, 2018GXNSFBA281074) and the Science and Technology Project of Guangxi (grant no. GKAD19110041, GKAD19110087).

\section{Data Availability Statement}

All data included in this study are available upon request by contact with the corresponding authors.

\section{References}

[1] Peng X, Guo Q, Liang X, Deng Y, Gu Y, Xu G, Yin Z. Mechanical properties, corrosion behavior and microstructures of a non-isothermal ageing treated Al-Zn-Mg-Cu alloy. Mater. Sci. Eng. A 688 (2017) $146^{\sim} 154$.

[2] Jiang J T, Xiao W Q, Yang L, Shao W Z, Yuan S J, Zhen L. Ageing behavior and stress corrosion cracking resistance of a non-isothermally aged Al-Zn-Mg-Cu alloy. Mater. Sci. Eng. A 605 (2014) 167 175.

[3] Wei L, Pan Q, Huang H, Feng L, Wang Y. Influence of grain structure and crystallographic orientation on fatigue crack propagation behavior of 7050 alloy thick plate. Int. J. Fatigue 66 (2014) 55 64.

[4] Lin Z, Sun G. Regression analysis of the influences of minor additions $\mathrm{Cu}$ and $\mathrm{Zr}$ on weld cracking sensitivity in Al-Zn-Mg alloys. Journal of Northeastern University 2 (1982) 93 102.

[5] Xu W F, Luo Y X, Fu M W. Microstructure evolution in the conventional single side and bobbin tool friction stir welding of thick rolled 7085-T7452 aluminum alloy. Mater. Charact. 138 (2018) 48 55.

[6] Liu Z, Zhang H, Feng H, Yan Z, Dong P. Effects of surface gradient nanostructuring on the fatigue behavior of the friction stir welded Al-Zn-Mg-Cu alloy. Mater. Lett. 252 (2019) 329 332.

[7] Zhang F, Su X, Chen Z, Nie Z. Effect of welding parameters on microstructure and mechanical properties of friction stir welded joints of a super high strength Al-Zn-Mg-Cu aluminum alloy. Materials \& Design 67 (2015) 483 491.

[8] Mao Y, Ke L, Chen Y, Liu F, Xing L. Inhomogeneity of microstructure and mechanical properties in the nugget of friction stir welded thick 7075 aluminum alloy joints. J. Mater. Sci. Technol. 34 (2018) 228 236.

[9] Zhao Y, Yang Z, Domblesky J P, Han J, Li Z, Liu X. Investigation of through thickness microstructure and mechanical properties in friction stir welded 7N01 aluminum alloy plate. Mater. Sci. Eng. A 760 (2019) $316^{\sim} 327$.

[10] Xu W F, Wu X K, Ma J, Lu H J, Luo Y X. Abnormal fracture of 7085 high strength aluminum alloy thick plate joint via friction stir welding. Journal of Materials Research and Technology 8 (2019) 6029 6040.

[11] Khan N Z, Siddiquee A N, Khan Z A, Mukhopadhyay A K. Mechanical and microstructural behavior of friction stir welded similar and dissimilar sheets of AA2219 and AA7475 aluminium alloys. J. Alloy. Compd. 695 (2017) 2902 2908. 
[12] Mastanaiah P, Sharma A, Reddy G M. Role of hybrid tool pin profile on enhancing welding speed and mechanical properties of AA2219-T6 friction stir welds. J. Mater. Process. Tech. 257 (2018) 257 269.

[13] Mishra R S, Ma Z Y. Friction stir welding and processing. Materials Science and Engineering: R: Reports 50 (2005) $1^{\sim} 78$.

[14] Sree Sabari S, Malarvizhi S, Balasubramanian V. Characteristics of FSW and UWFSW joints of AA2519T87 aluminium alloy: Effect of tool rotation speed. Journal of Manufacturing Processes 22 (2016) 278 289.

[15] Jiang J, Jiang F, Zhang M, Tang Z, Tong M. Recrystallization behavior of Al-Mg-Mn-Sc-Zr alloy based on two different deformation ways. Mater. Lett. 265 (2020) 127455.

[16] Huang H, Jiang F, Zhou J, Wei L, Zhong M, Liu X. Hot deformation behavior and microstructural evolution of as-homogenized $\mathrm{Al}-6 \mathrm{Mg}-0.4 \mathrm{Mn}-0.25 \mathrm{Sc}-0.1 \mathrm{Zr}$ alloy during compression at elevated temperature. J. Alloy. Compd. 644 (2015) 862 872.

[17] Chen Y, Liu C Y, Zhang B, Ma Z Y, Zhou W B, Jiang H J, Huang H F, Wei L L. Effects of friction stir processing and minor Sc addition on the microstructure, mechanical properties, and damping capacity of $7055 \mathrm{Al}$ alloy. Mater. Charact. 135 (2018) 25 31.

[18] Mo Y F, Liu C Y, Teng G B, Jiang H J, Chen Y, Yang Z X, Chen Y, Han S C. Fabrication of 7075-0.25Sc0.15Zr Alloy with Excellent Damping and Mechanical Properties by FSP and T6 Treatment. J. Mater. Eng. Perform. 27 (2018) 4162 4167.

[19] Zou Y, Cao L, Wu X, Wang Y, Sun X, Song H, Couper M J. Effect of ageing temperature on microstructure, mechanical property and corrosion behavior of aluminum alloy 7085. J. Alloy. Compd. 823 (2020) 153792 .

[20] Wang Y, Cao L, Wu X, Tong X, Liao B, Huang G, Wang Z. Effect of retrogression treatments on microstructure, hardness and corrosion behaviors of aluminum alloy 7085. J. Alloy. Compd. 814 (2020) 152264 .

[21] Nie B, Liu P, Zhou T. Effect of compositions on the quenching sensitivity of 7050 and 7085 alloys. Mater. Sci. Eng. A 667 (2016) 106 114.

[22] Xu W, Luo Y, Zhang W, Fu M. Comparative study on local and global mechanical properties of bobbin tool and conventional friction stir welded 7085-T7452 aluminum thick plate. J. Mater. Sci. Technol. 34 (2018) $173^{\sim} 184$.

[23] Xu W, Wang H, Luo Y, Li W, Fu M W. Mechanical behavior of 7085-T7452 aluminum alloy thick plate joint produced by double-sided friction stir welding: Effect of welding parameters and strain rates. Journal of Manufacturing Processes 35 (2018) 261 270.

[24] Xu W, Zhang W, Wu X. Corrosion Behavior of Top and Bottom Surfaces for Single-Side and DoubleSide Friction Stir Welded 7085-T7651 Aluminum Alloy Thick Plate Joints. Metallurgical and Materials Transactions A 48 (2017) 1078 1091.

[25] Wen K, Xiong B, Zhang Y, Li Z, Li X, Huang S, Yan L, Yan H, Liu H. Over-aging influenced matrix precipitate characteristics improve fatigue crack propagation in a high $\mathrm{Zn}$-containing $\mathrm{Al}-\mathrm{Zn}-\mathrm{Mg}-\mathrm{Cu}$ alloy. Mater. Sci. Eng. A 716 (2018) 42 54.

[26] Yang W, Ji S, Wang M, Li Z. Precipitation behaviour of Al-Zn-Mg-Cu alloy and diffraction analysis from $\eta$ ' precipitates in four variants. J. Alloy. Compd. 610 (2014) 623 629.

[27] Chung T, Yang Y, Huang B, Shi Z, Lin J, Ohmura T, Yang J. Transmission electron microscopy investigation of separated nucleation and in-situ nucleation in AA7050 aluminium alloy. Acta Mater. 149 (2018) $377^{\sim} 387$. 
[28] Liu J Z, Chen J H, Yang X B, Ren S, Wu C L, Xu H Y, Zou J. Revisiting the precipitation sequence in Al-Zn-Mg-based alloys by high-resolution transmission electron microscopy. Scripta Mater. 63 (2010) $1061^{\sim} 1064$.

[29] Jiang H J, Liu C Y, Chen Y, Yang Z X, Huang H F, Wei L L, Li Y B, Qi H Q. Evaluation of microstructure, damping capacity and mechanical properties of Al-35Zn and Al-35Zn-0.5Sc alloys. J. Alloy. Compd. 739 (2018) 114 121.

[30] Chen S, Chen K, Peng G, Jia L, Dong P. Effect of heat treatment on strength, exfoliation corrosion and electrochemical behavior of 7085 aluminum alloy. Materials \& Design 35 (2012) 93 98.

[31] Yadav V K, Gaur V, Singh I V. Effect of post-weld heat treatment on mechanical properties and fatigue crack growth rate in welded AA-2024. Mater. Sci. Eng. A 779 (2020) 139116.

[32] Ahmed M M Z, Ataya S, El-Sayed Seleman M M, Ammar H R, Ahmed E. Friction stir welding of similar and dissimilar AA7075 and AA5083. J. Mater. Process. Tech. 242 (2017) 77 91.

[33] Carlone P, Citarella R, Sonne M R, Hattel J H. Multiple crack growth prediction in AA2024-T3 friction stir welded joints, including manufacturing effects. Int. J. Fatigue 90 (2016) $69^{\sim} 77$.

[34] XU W, LIU J. Microstructure evolution along thickness in double-side friction stir welded $7085 \mathrm{Al}$ alloy. T. Nonferr. Metal. Soc. 25 (2015) 3212 3222.

[35] Liu S, Zhong Q, Zhang Y, Liu W, Zhang X, Deng Y. Investigation of quench sensitivity of high strength Al-Zn-Mg-Cu alloys by time-temperature-properties diagrams. Materials \& Design 31 (2010) 3116 3120.

[36] Zhao H, Chen Y, Gault B, Makineni S K, Ponge D, Raabe D. (Al, Zn)3Zr dispersoids assisted ${ }^{\prime}$ precipitation in anAl-Zn-Mg-Cu-Zr alloy. Materialia 10 (2020) 100641.

[37] Chiu Y, Du K, Bor H, Liu G, Lee S. The effects of Cu, Zn and Zr on the solution temperature and quenching sensitivity of Al-Zn-Mg-Cu alloys. Mater. Chem. Phys. 247 (2020) 122853.

[38] Zhao J, Liu Z, Bai S, Zeng D, Luo L, Wang J. Effects of natural aging on the formation and strengthening effect of G.P. zones in a retrogression and re-aged Al-Zn-Mg-Cu alloy. J. Alloy. Compd. 829 (2020) 154469.

[39] Wei L, Pan Q, Huang H, Feng L, Wang Y. Influence of grain structure and crystallographic orientation on fatigue crack propagation behavior of 7050 alloy thick plate. Int. J. Fatigue 66 (2014) 55 64.

[40] Zhang L, Zhong H, Li S, Zhao H, Chen J, Qi L. Microstructure, mechanical properties and fatigue crack growth behavior of friction stir welded joint of 6061-T6 aluminum alloy. Int. J. Fatigue 135 (2020) 105556.

[41] Bray G H, Glazov M, Rioja R J, Li D, Gangloff R P. Effect of artificial aging on the fatigue crack propagation resistance of 2000 series aluminum alloys. Int. J. Fatigue 23 (2001) 265 276 .

[42] Liu M, Liu Z, Bai S, Xia P, Ying P, Zeng S. Solute cluster size effect on the fatigue crack propagation resistance of an underaged Al-Cu-Mg alloy. Int. J. Fatigue 84 (2016) 104 112.

[43] Kamp N, Gao N, Starink M J, Sinclair I. Influence of grain structure and slip planarity on fatigue crack growth in low alloying artificially aged 2xxx aluminium alloys. Int. J. Fatigue 29 (2007) 869 878.

[44] Liu Z, Li F, Xia P, Bai S, Gu Y, Yu D, Zeng S. Mechanisms for Goss-grains induced crack deflection and enhanced fatigue crack propagation resistance in fatigue stage II of an AA2524 alloy. Mater. Sci. Eng. A 625 (2015) $271^{\sim} 277$.

[45] Hornbogen E, Gahr K Z. Microstructure and fatigue crack growth in a $\gamma$-Fe-Ni-Al alloy. Acta Metallurgica 24 (1976) 581 592. 